\title{
STRONTIUM DISTRIBUTION COEFFICIENTS OF BASALT AND SEDIMENT INFILL SAMPLES FROM THE IDAHO NATIONAL ENGINEERING AND ENVIRONMENTAL LABORATORY, IDAHO
}

U.S. GEOLOGICAL SURVEY

WATER-RESOURCES INVESTIGATIONS REPORT 99-4145
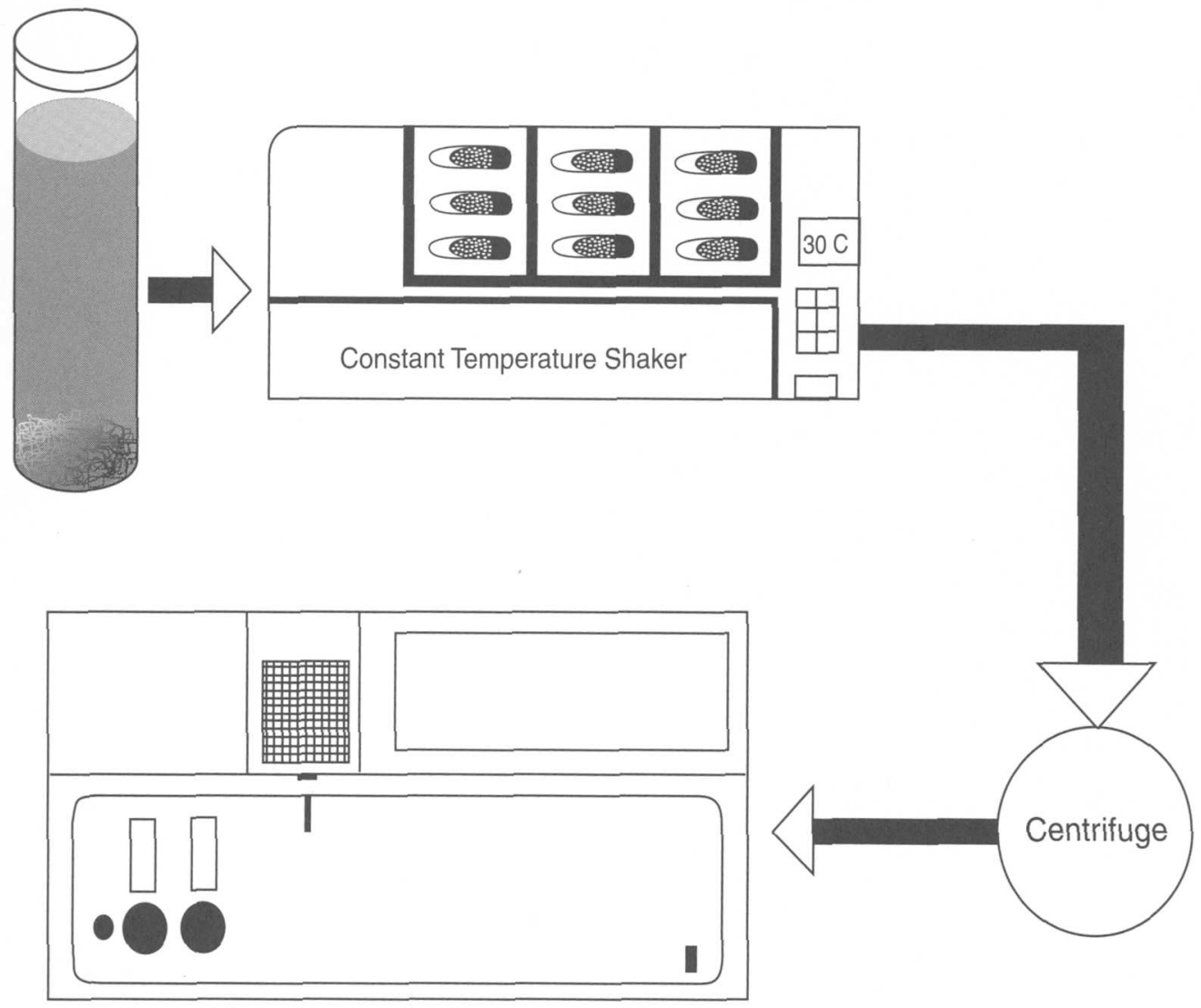

Prepared in cooperation with the U.S. DEPARTMENT OF ENERGY

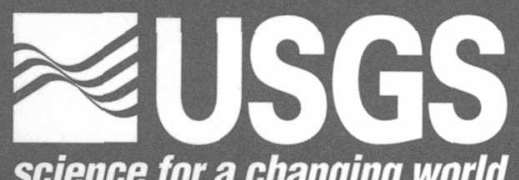




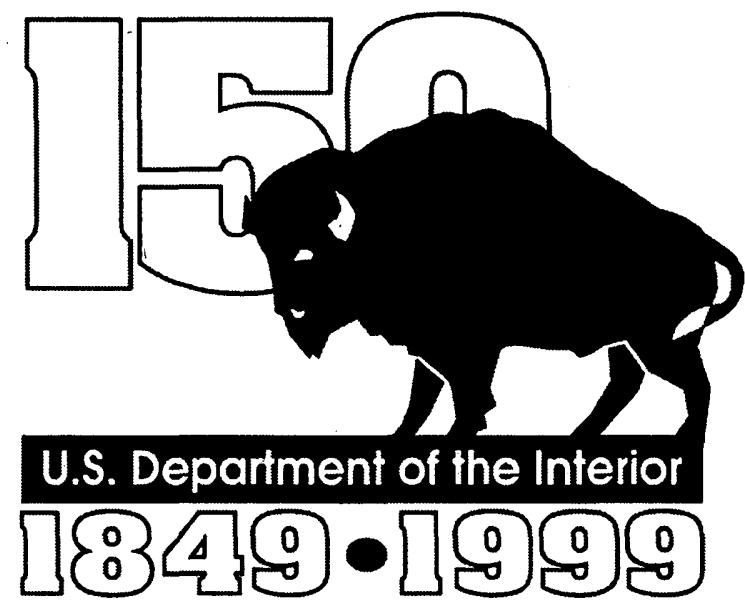

Cover: Graphical representation of batch experiments showing test tube containing water and core sample, constant-temperature shaker, centrifuge, and spectrometer. 


\section{Strontium Distribution Coefficients of Basalt and Sediment Infill Samples from the Idaho National Engineering and Environmental Laboratory, Idaho}

By: Mary N. Pace, U.S. Geological Survey;

Jeffrey J. Rosentreter, Idaho State University; and

Roy C. Bartholomay, U.S. Geological Survey

\section{U.S. GEOLOGICAL SURVEY}

Water-Resources Investigations Report 99-4145

Prepared in cooperation with

the U.S. DEPARTMENT OF ENERGY 


\section{U.S. DEPARTMENT OF THE INTERIOR BRUCE BABBITT, Secretary}

\section{U.S. GEOLOGICAL SURVEY}

Charles G. Groat, Director

Any use of trade, product, or firm names is for descriptive purposes only and does not imply endorsement by the U.S. Government.

For additional information write to:

U.S. Geological Survey

INEEL, MS 1160

P.O. Box 2230

Idaho Falls, ID 83403-2230
Copies of this report can be purchased from:

U.S. Geological Survey

Information Services

Box 25286, Denver Federal Center

Denver, CO 80225 


\section{CONTENTS}

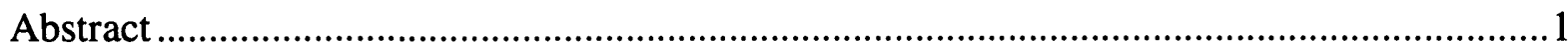

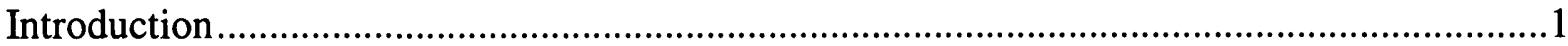

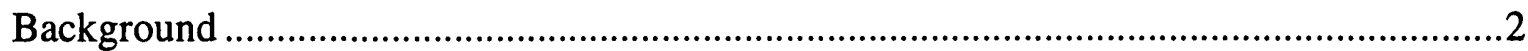

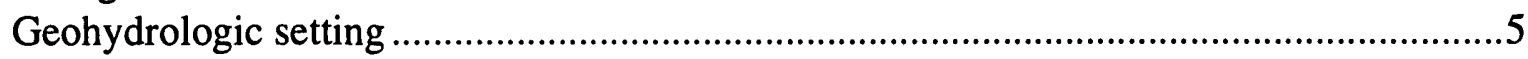

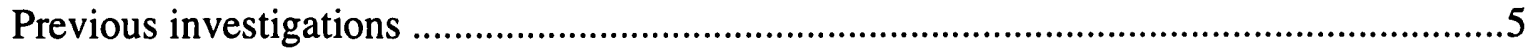

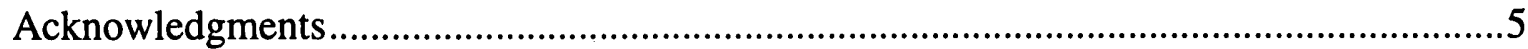

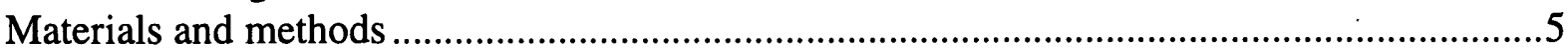

Collection, description, and preparation of samples ...........................................................6

Preparation of the synthesized aqueous solution ................................................................6

Experimental methods.....................................................................................................

Derivation of the strontium distribution coefficient using the linear sorption

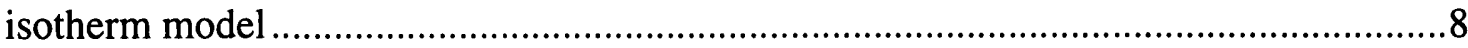

Strontium distribution coefficients of basalt, sediment infill, and standard material

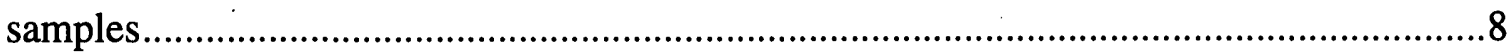

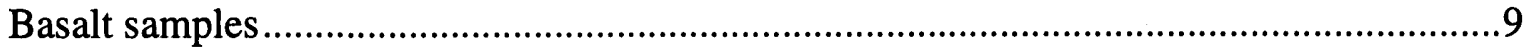

Sediment infill samples ............................................................................................

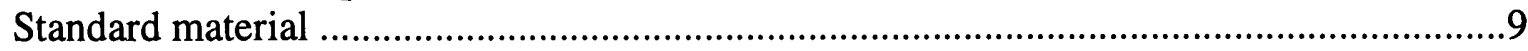

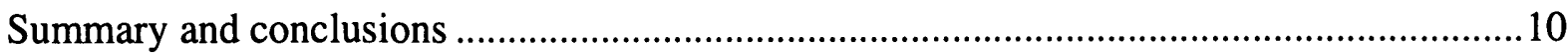

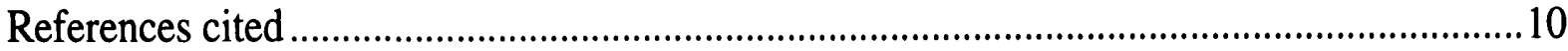

\section{FIGURES}

1. Map showing location of the Idaho National Engineering and Environmental Laboratory and selected facilities.

2. Map showing location of the Idaho Nuclear Technology and Engineering Center, Test Reactor Area,-waste-disposal sites, and core-sample collection site, Idaho National Engineering and Environmental Laboratory

\section{TABLES}

1. Bulk mineralogy of sediment infill samples from the Idaho National Engineering and Environmental Laboratory and of reference clay mineral samples

2. Brunauer-Emmett-Teller surface-area analysis of selected samples used in batch experiments

3. Whole-rock analysis for selected major, minor, and trace elements in selected samples used in batch experiments

4. Concentrations of alkalinity, aluminum, calcium, iron, magnesium, manganese, potassium, silica, sodium, strontium, and $\mathrm{pH}$ in the synthesized aqueous solutions used in the strontium batch experiments

5. Concentrations of alkalinity, calcium, magnesium, potassium, silica, sodium, and strontium, and $\mathrm{pH}$ in samples collected from waste-disposal ponds at the Idaho Nuclear Technology and Engineering Center 
6. Calculated and measured strontium distribution coefficients of basalt samples from the Idaho National Engineering and Environmental Laboratory

7. Basalt sample mass; initial and final concentrations of aluminum, calcium, sodium, iron, magnesium, potassium, manganese, and strontium; initial and final $\mathrm{pH}$ and conductivity; and measured distribution coefficients

8. Strontium distribution coefficients and standard error of basalt samples compared with previously analyzed basalt samples with sediment infill

9. Calculated and measured strontium distribution coefficients of sediment infill samples from the Idaho National Engineering and Environmental Laboratory

10. Sediment infill sample mass; initial and final concentrations of aluminum, calcium, sodium, iron, magnesium, potassium, manganese, and strontium; initial and final $\mathrm{pH}$ and conductivity; and measured strontium distribution coefficients

11. Strontium distribution coefficients and standard errors for sediment infill samples and selected interbedded sediment samples.

12. Calculated and measured strontium distribution coefficients of standard material samples.

13. Standard material sample mass; initial and final concentrations of aluminum, calcium, sodium, iron, magnesium, potassium, manganese, and strontium, initial and final $\mathrm{pH}$ and conductivity; and measured strontium distribution coefficients

\section{CONVERSION FACTORS AND ABBREVIATED UNITS}

\begin{tabular}{lcl}
\hline Multiply & By & To obtain \\
\hline cubic centimeter $\left(\mathrm{cm}^{3}\right)$ & 0.06102 & cubic inch \\
gram $(\mathrm{g})$ & .03527 & ounce \\
kilogram $(\mathrm{kg})$ & 2.205 & pound \\
kilometer $(\mathrm{km})$ & .6214 & mile \\
square kilometer $\left(\mathrm{km}^{2}\right)$ & .3861 & square mile \\
meter $(\mathrm{m})$ & 3.281 & foot \\
millimeter $(\mathrm{mm})$ & .0394 & inch \\
becquerel per liter $(\mathrm{Bq} / \mathrm{L})$ & .027 & picocurie per liter \\
terra becquerel $(\mathrm{TBq})$ & 27 & curie \\
\hline
\end{tabular}

For temperature, degrees Celsius $\left({ }^{\circ} \mathrm{C}\right)$ can be converted to degrees Fahrenheit $\left({ }^{\circ} \mathrm{F}\right)$ by using the formula ${ }^{\circ} \mathrm{F}=(1.8)\left({ }^{\circ} \mathrm{C}\right)+32$.

Abbreviated units used in report: $\mathrm{K}_{\mathrm{d}}$ (distribution coefficient), $\mathrm{mg} / \mathrm{L}$ (milligrams per liter), $\mathrm{mL} / \mathrm{g}$ (milliliters per gram), $\mathrm{mg} / \mathrm{kg}$ (milligrams per kilogram), $\mathrm{m}^{2} / \mathrm{g}$ (meters squared per gram). 


\title{
Strontium Distribution Coefficients of Basalt and Sediment Infill Samples from the Idaho National Engineering and Environmental Laboratory, Idaho
}

\author{
By Mary N. Pace, U.S. Geological Survey; Jeffrey J. Rosentreter, Idaho State University; \\ and Roy C. Bartholomay, U.S. Geological Survey
}

\section{Abstract}

The U.S. Geological Survey and Idaho State University, in cooperation with the U.S. Department of Energy, are conducting a study to determine and evaluate strontium distribution coefficients $\left(\mathrm{K}_{\mathrm{d}} \mathrm{s}\right)$ of subsurface materials at the Idaho National Engineering and Environmental Laboratory (INEEL). The purpose of this study is to aid in assessing the variability of strontium $\mathrm{K}_{d} \mathrm{~s}$ at the INEEL as part of an ongoing investigation of chemical transport of strontium-90 in the Snake River Plain aquifer. Batch experimental techniques were used to determine $K_{d} s$ of six basalt core samples, five samples of sediment infill of vesicles and fractures, and six standard material samples. The basalt and sediment infill samples were collected from a selected site at the INEEL. Batch experimental techniques were used to determine strontium $K_{d} s$ of the samples by using synthesized aqueous solutions representative of wastewater in disposal ponds at the INEEL. Calculated strontium $\mathrm{K}_{\mathrm{d}} \mathrm{S}$ of the sediment infill samples ranged from $201.6 \pm 10.8$ to $356.2 \pm 8.4$ milliliters per gram (mL/g). Calculated strontium $\dot{K}_{d}$ s of the basalt samples ranged from $1.3 \pm 8.4$ to $9.3 \pm 9.8 \mathrm{~mL} / \mathrm{g}$. The differences in strontium $K_{d} s$ arise from the variations in chemical composition and preparation of samples. The sorption process that occurs, physisorption or ion exchange, depends largely on the type of the sample material. Analyses of data from these experiments indicate that the $\mathrm{K}_{\mathrm{d}} \mathrm{s}$ of the sediment infill samples are significantly larger than those of the basalt samples. Quantification of such information is essential for furthering the under- standing of transport processes of strontium-90 in the Snake River Plain aquifer and in similar environments.

\section{INTRODUCTION}

The transport and fate of waste constituents in geologic material are dependent on chemical and physical processes that govern the distribution of constituents between the solid, geologic, stationary phase and an aqueous, mobile phase. This distribution often is quantified, at thermodynamic equilibrium, by an empirically determined parameter called the distribution coefficient $\left(K_{d}\right) . K_{d} s$ can be used effectively to summarize the chemical factors that affect transport efficiency of ground-water constituents. Many transport models for radionuclides use $K_{d} s$ to predict the extent to which the migration of the constituent will be lessened relative to the mean ground-water velocity (Bohn, 1985, p. 153-207; Sposito, 1989, p. 150-155; Fetter, 1993, p. 117-127).

The U.S. Geological Survey (USGS) and Idaho State University (ISU), in cooperation with the U.S. Department of Energy (DOE), are conducting a study to determine geochemical properties that affect strontium transport in basalt and sediment at the Idaho National Engineering and Environmental Laboratory (INEEL), Idaho. The purpose of the study is to determine the fate and transport behavior of chemical constituents in wastewater discharged to infiltration ponds and to the eastern Snake River Plain aquifer at the INEEL. Study objectives include assessing the 
variability of strontium $K_{d} s$ of basalt and sediment infill of vesicles and fractures in basalt at the INEEL.

This report presents experimentally derived strontium $\mathrm{K}_{\mathrm{d}} \mathrm{s}$ of six basalt core samples and five sediment infill samples collected from the Idaho Nuclear Technology and Engineering Center (INTEC), formerly the Idaho Chemical Processing Plant, at the INEEL, five standard clay mineral samples from the clay repository at the University of Missouri, and one standard calcite sample from the Geology Department at ISU. Basalt with no vesicle infill and sediment infill samples were collected because these types of materials have not been previously analyzed in this project. The basalt samples were cleaned of sediment infill to determine if there is any variability in strontium $K_{d} s$ from these type of samples to previously analyzed basalt samples which contained sediment infill material (Colello and others, 1998). The strontium $\mathrm{K}_{d} \mathrm{~s}$ of sediment infill samples were done to determine if any variability exists between strontium $\mathrm{K}_{\mathrm{d}} \mathrm{S}$ of the infill material to previously analyzed strontium $\mathrm{K}_{d}$ s of surficial and interbedded sediment (Liszewski and others, 1997, 1998). The $\mathrm{K}_{d} \mathrm{~s}$ of standard clay mineral and calcite samples were determined as reference for $\mathrm{K}_{\mathrm{d}} \mathrm{s}$ of the sediment infill samples. All samples were mixed with synthesized aqueous solutions, and batch experimental techniques were used to determine the distribution of strontium between the solid and aqueous phases. Concentrations of major cations and $\mathrm{pH}$ in the synthesized aqueous solutions were representative of concentrations in wastewater in disposal ponds at the INEEL. Strontium concentrations in the solutions were varied to define strontium-sorption isotherms. Strontium $K_{d} s$ were calculated from the isotherms by using the linear isotherm model described by Fetter (1993, p. 117-119).

\section{Background}

The INEEL comprises $2,300 \mathrm{~km}^{2}$ of the eastern Snake River Plain in southeastern Idaho (fig. 1). The INEEL was established in 1949 by the U.S. Atomic Energy Commission (now known as the DOE) for the development of peacetime atomicenergy applications such as nuclear-safety research, defense programs, and advanced energy concepts. More than 50 nuclear reactors have been operated at the INEEL since its inception. Facilities at the INEEL also are used to store nuclear waste, such as spent fuel rods from the U.S. Navy's nuclear fleet and other DOE sites, and wastes generated onsite.

Aqueous chemical and radiochemical wastes, including strontium- $90\left({ }^{90} \mathrm{Sr}\right)$, have been discharged to wastewater-disposal ponds and wells at the INEEL since 1952. Before February 1984, much of the wastewater discharged at the INTEC (fig. 2) was injected directly into the eastern Snake River Plain aquifer through a deep injection well. Since 1984, most of the wastewater has been discharged to unlined infiltration ponds. Some chemical constituents from wastewater can enter the aquifer indirectly following percolation from the infiltration ponds through sediments and basalt layers in the unsaturated zone (Pittman and others, 1988). Disposal of radioactive wastewater to the ponds at the Test Reactor Area (TRA) (fig. 2) ceased in August 1993 and the ponds were remediated (Eddie Chew, U.S. Department of Energy, written commun., 1995). Radioactive wastewater at the TRA now is discharged into two lined evaporation ponds.

Strontium-90, a radionuclide produced by the fission of uranium, has a half-life of 28.8 years and decays through beta emission (Eisenbud, 1973, p. 83-97). Global deposition of ${ }^{90} \mathrm{Sr}$ is well documented (Eisenbud, 1973, p. 320-331). This radionuclide is present in ground water and was introduced to the environment by fallout from nuclear explosions and as a result of the waste-disposal practices used in the nuclear industry. Because of its tendency to concentrate uniformly throughout mineral bone tissues, ${ }^{90} \mathrm{Sr}$ is a health hazard. The maximum contaminant level allowable in drinking water is about $0.3 \mathrm{~Bq} / \mathrm{L}$ (U.S. Environmental Protection Agency, 1989, p. 551).

Approximately 5.6 TBq of ${ }^{90} \mathrm{Sr}$ was discharged to the subsurface at the INEEL from the early 1950's to 1995 , primarily at the INTEC and TRA facilities (Bartholomay and others, 1997, p. 30). Documented disposals include $1.2 \mathrm{TBq}$ of ${ }^{90} \mathrm{Sr}$ discharged into a pit at the INTEC during 1962-63 (Robertson and others, 1974, p. 119); 0.9 TBq of 


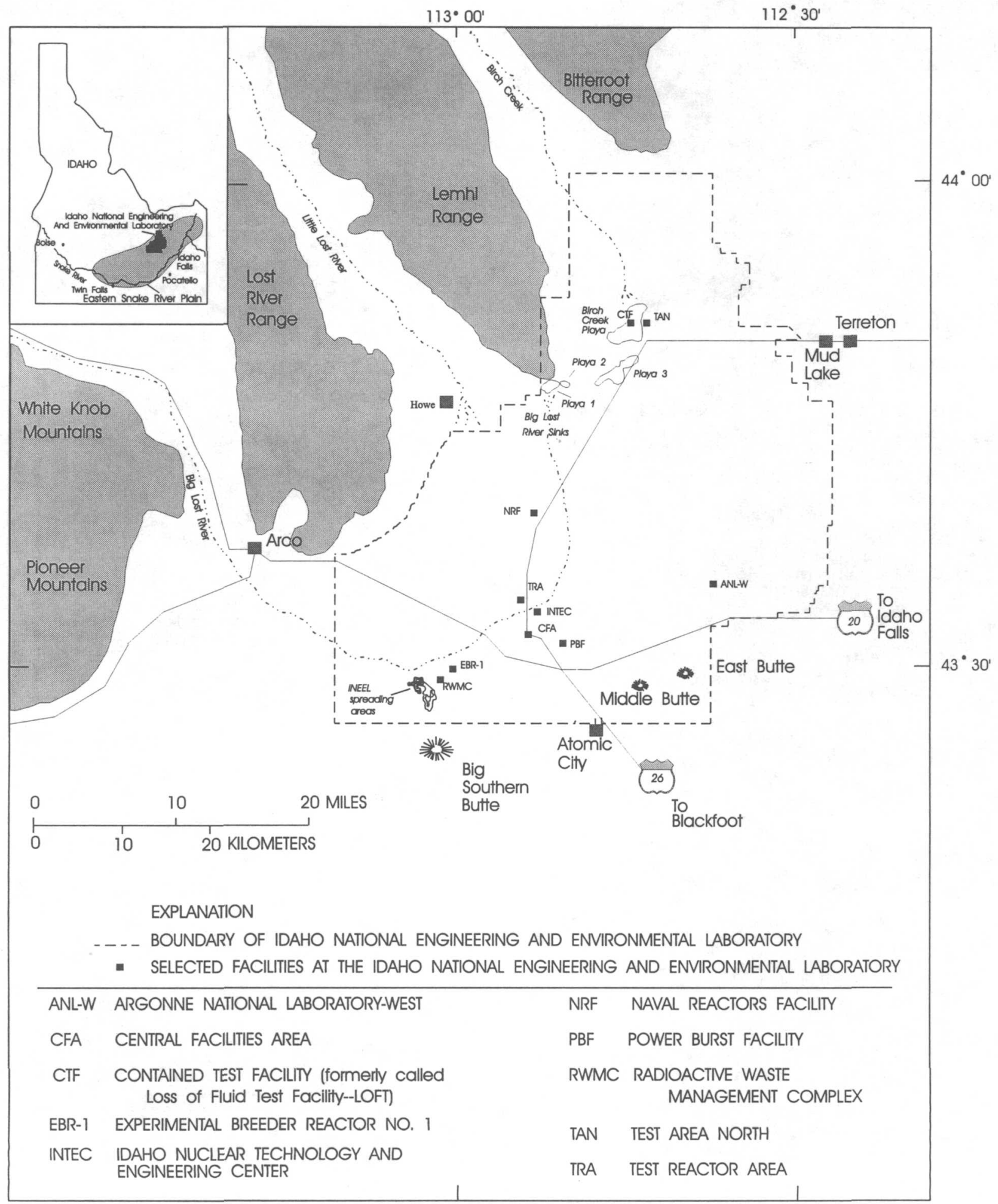

Figure 1. Location of the Idaho National Engineering and Environmental Laboratory and selected facilities. 


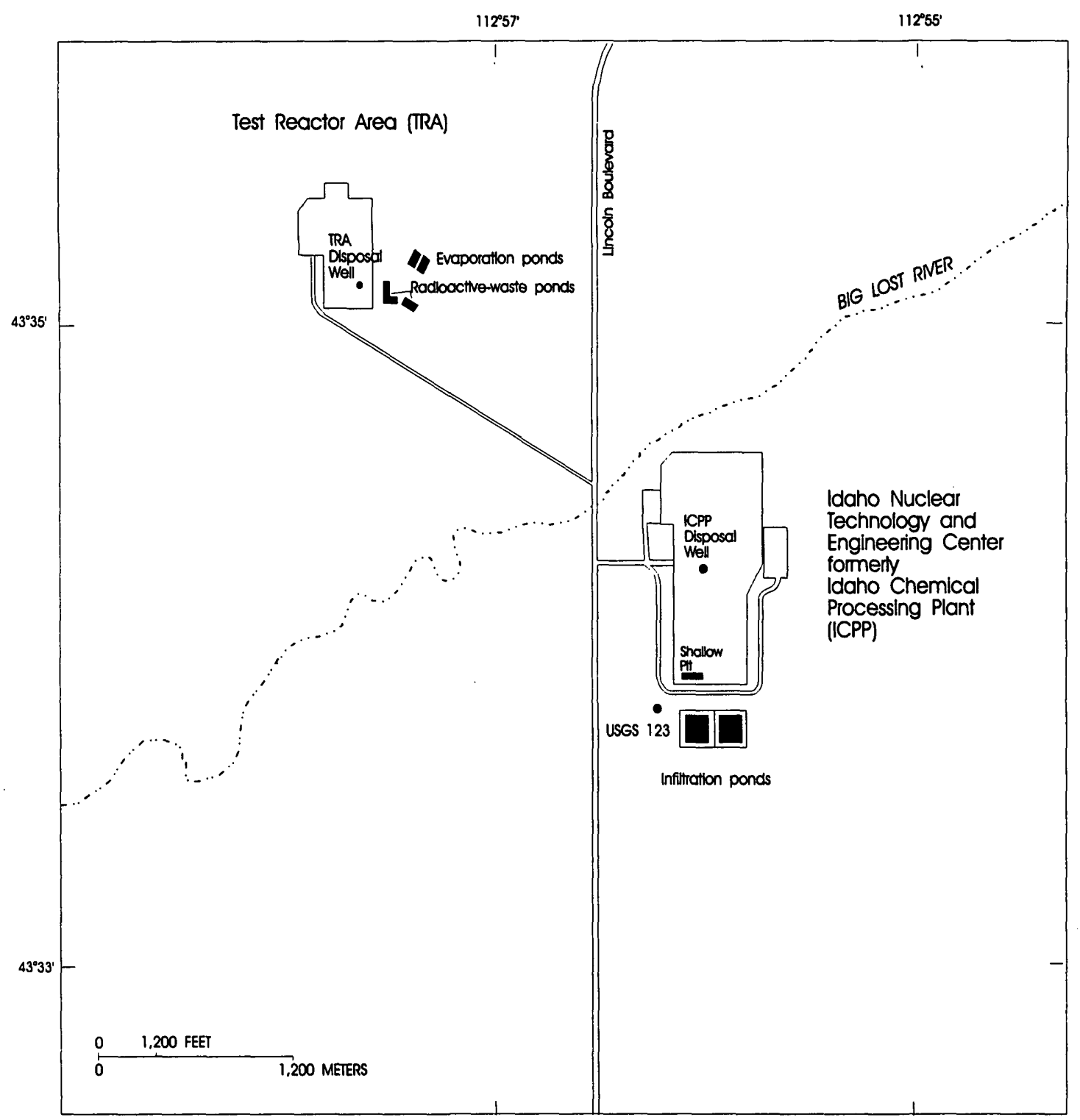

Figure 2. Location of the Idaho Nuclear Technology and Engineering Center, Test Reactor Area, waste-disposal sites, and core-sample collection site, Idaho National Engineering and Environmental Laboratory. 
${ }^{90} \mathrm{Sr}$ discharged to a disposal well and infiltration ponds at the INTEC (fig. 2) during 1952-95, of which approximately $0.02 \mathrm{TBq}$ was discharged to the waste-disposal ponds (Bartholomay and others, 1995, p. 21; Bartholomay and others, 1997, p. 30); and $3.4 \mathrm{TBq}$ of ${ }^{90} \mathrm{Sr}$ discharged to radioactivewaste disposal ponds at the TRA (fig. 2) during 1952-95 (Bartholomay and others, 1997, p. 30).

Concentrations of ${ }^{90} \mathrm{Sr}$ in perched ground water beneath the INTEC ranged from 0 to 0.63 $\pm 0.07 \mathrm{~Bq} / \mathrm{L}$ during 1992-95 (Bartholomay, 1998 , p. 24). Concentrations of ${ }^{90} \mathrm{Sr}$ in perched ground water beneath the TRA ranged from 0 to 5.3 $\pm 0.2 \mathrm{~Bq} / \mathrm{L}$ during the same period (Bartholomay, 1998, p. 16). Disposal of ${ }^{90} \mathrm{Sr}$ has resulted in concentrations larger than $0.3 \mathrm{~Bq} / \mathrm{L}$ in a $10-\mathrm{km}^{2}$ plume within the eastern Snake River Plain aquifer beneath the INTEC (Bartholomay and others, 1997, p. 33). In 1995, concentrations of ${ }^{90} \mathrm{Sr}$ in water from wells completed in the eastern Snake River Plain aquifer were as large as $2.8 \pm 0.1 \mathrm{~Bq} / \mathrm{L}$ (Bartholomay and others, 1997, p. 30). Strontium90 has not been detected within the eastern Snake River Plain aquifer beneath the TRA. This can, in part, be explained by the use of disposal ponds rather than the disposal well at this facility. Sorption processes in the unsaturated and perchedwater zones beneath the disposal ponds likely have lessened ${ }^{90} \mathrm{Sr}$ migration at the TRA. Also, more sediment is present beneath the TRA than beneath the INTEC (Anderson, 1991, p. 22-28).

\section{Geohydrologic Setting}

The eastern Snake River Plain is a northeasttrending structural basin about $320 \mathrm{~km}$ long and 80 to $110 \mathrm{~km}$ wide. The plain is underlain by a layered sequence of basaltic rocks and cinder beds intercalated with alluvial and lakebed deposits. Individual layers of basalt range from 3 to $15 \mathrm{~m}$ in thickness, although the average thickness can be from 6 to 8 m (Mundorf and others, 1964, p. 143). The sedimentary deposits consist mainly of lenticular beds of sand, silt, and clay, and lesser amounts of gravel. Locally, rhyolitic rocks and tuffs are exposed at the land surface or occur at depth. The basaltic rocks and intercalated sedimentary deposits combine to form the framework for the Snake River Plain aquifer system, which is the main source of ground water on the plain. The depth to water in the aquifer system ranges from about $60 \mathrm{~m}$ below land surface in the northern part of the INEEL to more than $275 \mathrm{~m}$ in the southern part (Bartholomay and others, 1997, p. 20). The general direction of groundwater flow is from the northeast to the southwest. The INEEL obtains its entire water supply from the eastern Snake River Plain aquifer.

\section{Previous Investigations}

Strontium $\mathrm{K}_{\mathrm{d}} \mathrm{s}$ of sediment collected from the INEEL have been reported by Hawkins and Short (1965), Schmalz (1972), Del Debbio and Thomas (1989), Newman and others (1996), Bunde and others $(1997,1998)$, Hemming and others (1997), and Liszewski and others $(1997,1998)$. Strontium $\mathrm{K}_{\mathrm{d}} \mathrm{s}$ of basalt collected at the INEEL have been reported by Del Debbio and Thomas (1989), Newman and others (1996), and Colello and others (1998). Strontium $K_{d} s$ of sediment from other nuclear facilities in the United States and Canada have been reported by Patterson and Spoel (1981), Jackson and Inch (1983), and Kipp and others (1986). A summary and review of available information published through 1976 of ${ }^{90} \mathrm{Sr}$ and other radionuclide interactions with geologic material were compiled by Ames and Rai (1978).

\section{Acknowledgments}

The authors gratefully acknowledge the assistance and cooperation of the ISU Department of Chemistry, Dr. Dennis Strommen, Chairman, for providing laboratory space and equipment. The authors are grateful to Dr. Lyle Castel, ISU Department of Chemistry, and Jaromy, Green, USGS, for technical review of the manuscript.

\section{MATERIALS AND METHODS}

Experiments for measuring $K_{d} s$ required the collection and preparation of core samples of basalt, and sediment infill of basalt samples and the preparation of the synthesized aqueous solution. Once the samples and solution were prepared, they 
were combined in centrifuge tubes and agitated using batch experimental techniques for a period of time sufficient for an apparent equilibrium to be reached. Solutions then were analyzed for dissolved-strontium content. The amount of strontium sorbed to the sample was calculated as the difference between the initial and equilibrium solution concentrations multiplied by the volume-to-mass ratio. Sorption isotherms and $K_{d} s$ then were calculated using the linear isotherm model (Fetter, 1993, p. 118).

\section{Collection, Description, and Preparation of Samples}

Basalt and sediment infill samples for this study were collected from core site USGS 123 near the INTEC (fig. 2). This core location was selected because radioactive wastewater containing ${ }^{90} \mathrm{Sr}$ has been discharged to the subsurface at the INTEC and strontium- 90 concentrations in the ground water have been above the maximum contaminant level for drinking water (Bartholomay and others, 1997).

Representative $10-\mathrm{cm}$ pieces of the core were collected using a core splitter, placed in a plastic bag, labeled, and transported to ISU for preparation and analysis. Sample selection criteria for USGS 123 were based on the location of the sample relative to the aquifer and to samples that had been used in previous experimentation to ensure that samples were well characterized. Core samples were collected from depths of 92.5 to $92.6,150.8$ to $150.9,153.4$ to $153.5,155.4,156.5$ to 156.6 , 157.6 to $157.8,163.2$, and 172.4 to $172.5 \mathrm{~m}$.

The selected cores were prepared for batch experiments by first removing the sediment infill from the basalt using an electronic etching device, taking care not to remove any basalt. The sediment infill then was placed in a separate bag and labeled. After the infill was removed, the outer rind of the core was removed and discarded. This was accomplished by placing the basalt core on the center of a clean, circular, steel plate and crushing the core with a clean hammer. Fragments containing exterior rind were removed from the sample to obtain basalt samples without contamination from the drill and sediment. Samples then were crushed to pass through a 2-mm sieve, packaged, and labeled. Bulk mineralogy of the sediment infill samples was determined using $\mathrm{X}$-ray diffraction techniques (Reed and Bartholomay, 1994, p. 5-6) (table 1). Basalt mineralogy was assumed to be consistent with that reported by Knobel and others (1997). Surface area of basalt and infill samples were determined by Brunauer-Emmett-Teller analysis (table 2) (Brunauer and others, 1938), and wholerock analysis was determined by inductively coupled plasma-mass spectroscopy (ICP-MS) (table 3 ). The standard clay mineral and calcite samples also were prepared and analyzed as described previously.

\section{Preparation of the Synthesized Aqueous Solution}

A synthesized aqueous solution that chemically represented wastewater in the INTEC infiltration ponds was prepared because of the difficulty in obtaining actual wastewater and potential chemical changes associated with the long-term storage of wastewater. The synthesized aqueous solution contained dissolved calcium, chloride, magnesium, potassium, sodium, strontium, silica, and carbonate alkalinity. The $\mathrm{pH}$ of the synthesized aqueous solution was fixed at $8.0 \pm 0.1$. The use of a synthesized aqueous solution allowed for the control of experimental variables, addressed potential saturation problems and chemical-phase modifications, and provided a constant supply of solution.

A concentrated stock solution containing 1,000 $\mathrm{mg} / \mathrm{L}$ of calcium, $200 \mathrm{mg} / \mathrm{L}$ of magnesium, and $200 \mathrm{mg} / \mathrm{L}$ of potassium was prepared by adding American Chemical Society (ACS)-certified reagents of calcium carbonate, magnesium carbonate, and potassium chloride along with concentrated trace-metal-grade hydrochloric acid to deionized water. A concentrated stock solution containing $1,000 \mathrm{mg} / \mathrm{L}$ of stable strontium was prepared separately by adding ACS-certified strontium carbonate and concentrated trace-metal-grade hydrochloric acid to deionized water. Stable strontium was substituted for the radioactive ${ }^{90} \mathrm{Sr}$ isotope so that no special handling was required. Stable strontium is assumed to behave geochemically in the same manner as ${ }^{90} \mathrm{Sr}$. Concentrated 
trace-metal-grade hydrochloric acid was added to the stock solutions to enhance their stability and to evolve carbon dioxide. The resulting $\mathrm{pH}$ of the concentrated stock solutions was less than 2.0.

Four volumetric flasks of the synthesized aqueous solution were prepared by first volumetrically diluting the concentrated stock solution of calcium, magnesium, and potassium with deionized water. The solution in each of the flasks then was spiked with different amounts of the strontium stock solution. Next, silica, in the form of sodium silicate, was added directly to the solutions using a Fisher Scientific 1,000-mg/L atomic-absorption reference standard. The $\mathrm{pH}$ then was adjusted to $8.0 \pm 0.1$ by adding 1.0 -molar sodium hydroxide and hydrochloric acid. Sodium then was added to the synthesized aqueous solutions in the form of solid sodium bicarbonate and the $\mathrm{pH}$ was readjusted to 8.0. Finally, the solutions were equilibrated with atmospheric gases by leaving the flasks open overnight and then readjusting the $\mathrm{pH}$, if necessary.

Two batches of the synthesized aqueous solution were prepared and spiked with strontium.

Actual concentrations of alkalinity, aluminum, calcium, iron, magnesium, manganese, potassium, silica, sodium, strontium, and $\mathrm{pH}$ are listed in table 4 . Small variations between constituent concentrations in the two batches resulted from inconsistencies in the preparation. Also, because the strontium concentrate used for spiking was acidified, each of the spiked solutions required different amounts of sodium hydroxide and hydrochloric acid for $\mathrm{pH}$ adjustment. Therefore, concentrations of sodium and chloride varied slightly in each solution. These variations were not expected to affect strontium sorption to a measurable degree. Chloride concentrations were not determined analytically. Target concentrations of calcium, magnesium, potassium, silica, sodium, and $\mathrm{pH}$ in the synthesized aqueous solution were based on typical concentrations of these constituents in historical wastewater samples from INTEC waste-disposal ponds. Historical pond-water analyses (table 5 ), presented as supporting data in this report, were performed by the U.S. Geological Survey's National Water Quality Laboratory using analytical techniques prescribed by Skougstad and others
(1979). Alkalinity concentrations were dependent on the amount of sodium bicarbonate added to the solution, as described previously.

\section{Experimental Methods}

The sorption studies were carried out using batch experimental techniques in $50-\mathrm{cm}^{3}$ polyethylene centrifuge tubes. Batch experiments were used because they are relatively simple and inexpensive, and many experiments can be done simultaneously. The basalt and sediment infill samples were homogenized and split into 1-g subsamples using a riffle splitter to minimize bias. Each 1-g subsample then was quartered into $0.25-\mathrm{g}$ samples. The 0.25 -g samples were equilibrated with 20.0 $\mathrm{mL}$ of the synthesized aqueous solution at $30^{\circ} \mathrm{C}$ in a constant-temperature shaker (Fisher Scientific Versa-Bath S Model 236) at a setting of 70 cycles per minute for about 120 hours. The mass-to-volume ratio was determined to be $0.25 \mathrm{~g}$ to $20 \mathrm{~mL}$ on the basis of the water saturation level of smectite (SWy-2), a source clay from the University of Missouri Clay Repository. The equilibrium time was demonstrated to be sufficient by kinetic work indicating that most surficial sorption was relatively rapid and nearly complete within 60 hours for basalt samples (Colello and others, 1998). The equilibration time of 120 minutes for the sediment infill samples and the standard clay mineral and calcite samples was determined to be sufficient from kinetic work performed in this phase of the experiment. The aqueous phase was separated from the solid phase at the end of the experiment by centrifugation for 15 minutes at 6,000 revolutions per minute and filtering through a glass-fiber filter. The supernatant samples were preserved by adding several drops of concentrated trace-metalgrade nitric acid.

Experiments were grouped into sets consisting of 12 samples mixed with synthesized aqueous solution in centrifuge tubes, three tubes of each of the four strontium concentrations in the synthesized aqueous solution. Additionally, an experimental blank and four control samples were included in each experimental set. The blank consisted of only deionized water in a centrifuge tube, and control samples consisted of only synthesized 
aqueous solution in centrifuge tubes, one at each of the four strontium concentrations. Blanks and controls provided experimental evidence that the constituents in these experiments did not adsorb onto or desorb from the reaction vessel-walls or experimental apparatus.

The synthesized aqueous solutions, controls, and blanks were analyzed for concentrations of alkalinity, aluminum, iron, calcium, magnesium, manganese, potassium, sodium, strontium, $\mathrm{pH}$, and specific conductance before and after equilibration with the samples. Cation concentrations were determined on a Perkin Elmer Plasma 400 Emission Spectrometer with Plasma 400 software Color version 4.10 (ICP) by using standard methods for metals in water (Greenberg and others, 1992); pH was measured using a YSI 3500 Water Quality Monitor pH meter; specific conductivity was measured using a Fischer Scientific conductivity meter; and alkalinity was determined using a Hach digital titrator.

Sorption isotherms for each sample were determined from strontium-distribution data for four initial target solution concentrations. Strontium linear sorption isotherms and $\mathrm{K}_{d} \mathrm{~s}$ were derived from the least-squares regression of equilibrium concentrations of strontium sorbed to the sample as a function of dissolved strontium in solution at equilibrium (Fetter, 1993, p. 118). Concentrations of dissolved strontium were measured directly on an ICP. Concentrations of sorbed strontium were calculated as the difference between the initial-solution and equilibrium-solution concentrations of dissolved strontium multiplied by the volume-tomass ratio. Initial concentrations were determined on the basis of the concentrations in control samples measured at the conclusion of the experiment. To best represent field conditions in the unsaturated and perched ground-water zones, the samples were not pretreated with the simulated-wastewater solution before experimentation.

\section{Derivation of the Strontium Distribution Coefficient Using the Linear Sorption Isotherm Model}

The measured distribution coefficient is defined by Kipp and others (1986, p. 523) as:

$$
\mathrm{K}_{\mathrm{d}}=[\mathrm{Sr}]_{\mathrm{s}} /[\mathrm{Sr}]_{\mathrm{eq}},
$$

where

$\mathrm{K}_{\mathrm{d}}$ is measured in milliliters per gram;

$$
\begin{aligned}
{[\mathrm{Sr}]_{\mathrm{S}}=} & \text { concentration of sorbed constituent per } \\
& \text { unit mass of basalt, in milligrams per } \\
& \text { kilogram; and } \\
{[\mathrm{Sr}]_{\mathrm{eq}}=} & \text { concentration of dissolved constituent } \\
& \text { in the equilibrated solution, in milli- } \\
& \text { grams per liter. }
\end{aligned}
$$

Equilibrium sorption of solutes on geologic material commonly is described by the linear sorption isotherm model, where the $K_{d}$ is equal to the slope of a least-squares fit between sorbed and aqueous strontium concentrations at thermodynamic equilibrium (Fetter, 1993, p. 118). Plots of isotherms for the materials used in this study indicated that these materials conform to the linear isotherm model better than to other models. Therefore, the slopes of the linear sorption isotherms were used to calculate the $\mathrm{K}_{\mathrm{d}} \mathrm{s}$ for this study.

Experimental values of $[\mathrm{Sr}]_{\mathrm{S}}$ were determined using assayed concentrations of aqueous strontium and ratios of solution to the materials used in experimentation:

$$
[\mathrm{Sr}]_{\mathrm{S}}=\left\{[\mathrm{Sr}]_{\mathrm{i}}-[\mathrm{Sr}]_{\mathrm{eq}}\right\} \mathrm{V} / \mathrm{M},
$$

where

$[\mathrm{Sr}]_{\mathrm{i}}=$ initial concentration of aqueous strontium in the solution before equilibration with the material, in milligrams per liter;

$$
\begin{aligned}
& \mathrm{V}=\text { volume of solution, in milliliters; and } \\
& \mathrm{M}=\text { mass of material, in grams. }
\end{aligned}
$$

\section{STRONTIUM DISTRIBUTION COEFFICIENTS OF BASALT, SEDIMENT INFILL, AND STANDARD MATERIAL SAMPLES}

Three types of geologic materials were selected for this experiment: basalt, sediment infill, and standard material consisting of reference clay minerals and calcite. Five sediment infill samples 
were selected to determine whether $\mathrm{Sr} \mathrm{K}_{d} \mathrm{~S}$ of sediment infill material differed from those of surficial and sediment interbeds. Six basalt samples were collected and sediment infill was removed from the basalt to contrast samples collected by Colello and others (1998). The reference clay mineral samples used in this study included two smectites (Swy-1 and SAz-1), two kaolinites (KGa-1b and $\mathrm{KGa}-2$ ), and an illite (Ilt-2). The standard clay materials and an additional sample of calcite were analyzed as reference samples for the sediment infill material. The calculated $\mathrm{K}_{\mathrm{d}} \mathrm{s}$ were determined from the slope of the linear isotherm model and the uncertainties are reflected as the standard error of the linear regression.

\section{Basalt Samples}

Table 6 lists each basalt sample and the calculated and measured strontium $K_{d}$ s. The calculated strontium $\mathrm{K}_{\mathrm{d}} \mathrm{s}$ of the six basalt samples ranged from $1.3 \pm 8.4$ to $9.3 \pm 9.8 \mathrm{~mL} / \mathrm{g}$. The measured strontium $\mathrm{K}_{d} \mathrm{~s}$, the average of three replicate determinations, ranged from $-67.55 \pm 10.03 \mathrm{~mL} / \mathrm{g}$ for a sample with the initial strontium concentration of 0 $\mathrm{mg} / \mathrm{L}$ to $9.97 \pm 1.48 \mathrm{~mL} / \mathrm{g}$ for a sample with the initial strontium concentration of $1 \mathrm{mg} / \mathrm{L}$ (table 6). The negative strontium $\mathrm{K}_{\mathrm{d}} \mathrm{s}$ of the samples containing initial strontium concentrations of $0 \mathrm{mg} / \mathrm{L}$ indicate that strontium was desorbing from the basalt samples at that concentration. The basalt sample mass, initial and final concentrations of aluminum, calcium, iron, magnesium, manganese, potassium, sodium, strontium, the initial and final $\mathrm{pH}$ and conductivity, and measured strontium $\mathrm{K}_{\mathrm{d}}$ s of each sample are presented in table 7 .

Table 8 lists the strontium $\mathrm{K}_{d} \mathrm{~s}$ and standard errors for the basalt samples analyzed for this study and the basalt samples containing sediment infill that were collected from the same core (USGS 123) and analyzed for a previous study. The standard errors for the basalt samples analyzed for this study were larger than the $K_{d} s$ themselves. The large standard errors resulted from the small rock: water ratio $(0.25 \mathrm{~g}: 20 \mathrm{~mL})$ used in these experiments which resulted in a small change in the strontium concentration to be measured. Standard errors of the previously analyzed basalt sam- ples were smaller than those of the samples analyzed in this study because the rock:water ratio ( $2 \mathrm{~g}: 20 \mathrm{~mL}$ ) was much larger. Despite the varying rock:water ratios, the $K_{d} s$ of the basalt samples from the two studies are in agreement.

\section{Sediment Infill Samples}

Table 9 lists calculated and measured $\mathrm{K}_{\mathrm{d}} \mathrm{s}$ of sediment infill samples. The calculated strontium $\mathrm{K}_{\mathrm{d}} \mathrm{s}$ of the five sediment infill samples ranged from $201.6 \pm 10.8$ to $356.2 \pm 8.4 \mathrm{~mL} / \mathrm{g}$. The measured strontium $\mathrm{K}_{d} \mathrm{~s}$, the average of three replicate determinations ranged from $-79.21 \pm 11.37 \mathrm{~mL} / \mathrm{g}$ for a sample with the initial strontium concentration of 0 $\mathrm{mg} / \mathrm{L}$ to $330.58 \pm 13.35 \mathrm{~mL} / \mathrm{g}$ for a sample with the initial strontium concentration of $5 \mathrm{mg} / \mathrm{L}$ (table 9 ). The negative strontium $K_{d} s$ of samples containing initial strontium concentrations of $0 \mathrm{mg} / \mathrm{L}$ indicate that strontium was desorbing from the sediment infill samples at that concentration. The sediment infill sample mass, initial and final concentrations of aluminum, calcium, iron, magnesium, manganese, potassium, sodium, strontium, the initial and final $\mathrm{pH}$ and conductivity, and measured strontium $\mathrm{K}_{\mathrm{d}} \mathrm{S}$ of each sample are presented in table 10 .

Liszewski and others (1998, p. 9) previously determined that $K_{d} s$ were larger for interbed sediments than surficial sediments, so a comparison of previously determined strontium $\mathrm{K}_{\mathrm{d}} \mathrm{s}$ of sediment interbed samples collected near the INTEC and sediment infill samples from this study is given in table 11. The $K_{d} s$ of the infill samples, were on the average, larger than the $K_{d} s$ of the sediment interbed samples (table 11). This might result from smaller, clay-sized particles percolating down through the basalt and filling the vesicles.

\section{Standard Material}

Table 12 lists calculated and measured strontium $K_{d}$ s for each standard material sample. The calculated strontium $\mathrm{K}_{d} \mathrm{~s}$ ranged from $-2.6 \pm 5.8$ to $752.2 \pm 21.4 \mathrm{~mL} / \mathrm{g}$. The measured strontium $\mathrm{K}_{\mathrm{d}} \mathrm{s}$, the average of three replicate determinations, ranged from $-79.02 \pm 0.18 \mathrm{~mL} / \mathrm{g}$ for a sample with the initial strontium concentration of $0 \mathrm{mg} / \mathrm{L}$ to 
$440.26 \pm 8.06 \mathrm{~mL} / \mathrm{g}$ for a sample with the initial strontium concentration of $5 \mathrm{mg} / \mathrm{L}$ (table 12 ). The negative strontium $K_{d} s$ of samples containing initial strontium concentrations of $0 \mathrm{mg} / \mathrm{L}$ indicate that strontium was desorbing from the standard clay mineral and calcite samples at that concentration. The sample mass, initial and final concentrations of aluminum, calcium, iron, magnesium, manganese, potassium, sodium, strontium, the initial and final conductivity and $\mathrm{pH}$, and measured strontium distribution coefficients for each sample are presented in table 13 .

Of the $K_{d} s$ determined for the standard clay minerals and calcite, the largest $K_{d}$ was for sample SAz-1 (Ca-montmorillonite from Arizona), and the smallest was for the calcite sample. Calcite $K_{d} s$ indicate that calcium competes with strontium for surface-sorption sites. As the amount of calcium in solution increases, less strontium sorbs to the material and sometimes desorbs, as evidenced by the negative strontium $K_{d} s . K_{d} s$ of standard clay mineral samples containing kaolinite and illite were smaller than $\mathrm{K}_{\mathrm{d}} \mathrm{s}$ of smectites because of the nature of the layering of the clay mineral sites. Mineralogy of sediment infill samples indicates abundant calcite and illite (table 1), which makes comparison of the $K_{d} s$ of these samples with those of the standard samples implausible.

\section{SUMMARY AND CONCLUSIONS}

The results of the basalt experiments show a relatively small range of distribution coefficients when compared to interbed (Liszewski and others, 1998) and vesicle and fracture infill sediments at the INEEL. The basalt $\mathrm{K}_{d} \mathrm{~s}$ ranged from $1.3 \pm 8.4$ to $9.3 \pm 9.8 \mathrm{~mL} / \mathrm{g} ; \mathrm{K}_{\mathrm{d}} \mathrm{s}$ of the interbed sediments ranged from $38 \pm 7$ to $328 \pm 41 \mathrm{~mL} / \mathrm{g}$ (Liszewski and others, 1998); and $K_{d}$ s of sediment infill samples ranged from $201.6 \pm 10.8$ to $356.2 \pm 8.4 \mathrm{~mL} / \mathrm{g}$. These results indicate that ion exchange is the prominent sorption mechanism in the sediment system. In contrast, basalts have low strontium sorption and show little evidence of exchangeable ions in the equilibrium solutions. The primary sorption mechanism for basalts is thought to be physisorption. Thus, $\mathrm{K}_{d} \mathrm{~s}$ of basalts are significantly lower than those of sediment.
The sorption process, in part, relates to the surface area of a material. $K_{d} s$ of materials that have small surface areas, such as basalt, are small, whereas $K_{d} s$ of materials that have large surface areas, such as the sediment infill and clays, are large. Sorption also is influenced by ion exchange. Hence, materials with high cation-exchange capacities, such as sediment infill and clays, have a large sorption capacity. Some cations, such as calcium, compete with strontium for surface sites. This is evident in the calcite batch experiment that resulted in a $\mathrm{K}_{\mathrm{d}}$ of $-2.6 \pm 5.8 \mathrm{~mL} / \mathrm{g}$ (table 12). The calcium ions in solution compete with strontium for surface sites and inhibit the sorption of strontium onto the rock material.

$\mathrm{K}_{d} \mathrm{~s}$ of sediment infill samples were larger than $\mathrm{K}_{\mathrm{d}} \mathrm{s}$ of the basalt and sediment interbed samples. The fact that the $K_{d} s$ of the sediment infill samples were larger than $\mathrm{K}_{\mathrm{d}} \mathrm{s}$ of interbedded sediment samples could be the result of fine-grained sediments (clay and silt-sized particles) infiltrating down through the basalt and filling vesicles and fractures in the basalt. Surface areas and ion-exchange capacities tend to be higher for clay-sized particles than for other particle sizes, which results in larger $\mathrm{K}_{\mathrm{d}} \mathrm{s}$.

The $\mathrm{K}_{\mathrm{d}} \mathrm{s}$ of the geological materials determined in this study indicate that more strontium is sorbed to the sediment in interbed layers and in fractures and vesicles of basalt than to basalt. The basalt rocks in the eastern Snake River Plain aquifer have small amounts of sediment in vesicles and fractures, which allows ${ }^{90} \mathrm{Sr}$ to be sorbed. Therefore, transport of ${ }^{90} \mathrm{Sr}$ is retarded by the sediment in the interbeds and vesicles and fractures of the basalt.

\section{REFERENCES CITED}

Ames, L.L., and Rai, D., 1978, Radionuclide interactions with soil and rock media, v. 1 of Processes influencing radionuclide mobility and retention, element chemistry and geochemistry, conclusions and evaluation: U.S. Environmental Protection Agency, EPA 520/6-78-007 [variously paged]. 
Anderson, S.R., 1991, Stratigraphy of the unsaturated zone and uppermost part of the Snake River Plain aquifer at the Idaho Chemical Processing Plant and Test Reactors Area, Idaho National Engineering Laboratory, Idaho: U.S. Geological Survey WaterResources Investigations Report 91-4010, 71 p.

Bartholomay, R.C., 1998, Distribution of selected radiochemical and chemical constituents in perched ground water at the Idaho National Engineering Laboratory, Idaho, 1992-95: U.S. Geological Survey Water-Resources Investigations Report 984026, $59 \mathrm{p}$.

Bartholomay, R.C., Orr, B.R., Liszewski, M.J., and Jensen, R.G., 1995, Hydrologic conditions and distribution of selected chemical constituents in water, Snake River Plain aquifer, Idaho National Engineering Laboratory, Idaho, 1989 through 1991: U.S. Geological Survey Water-Resources Investigations Report 95-4175, $47 \mathrm{p}$.

Bartholomay, R.C., Tucker, B.J., Ackerman, D.J., and Liszewski, M.J., 1997, Hydrologic conditions and distribution of selected radiochemical and chemical constituents in water, Snake River Plain aquifer, Idaho National Engineering Laboratory, Idaho, 1992 through 1995: U.S. Geological Survey WaterResources Investigations Report 97-4086, 57 p.

Bohn, H.L., 1985, Soil chemistry: New York, John Wiley and Sons, Inc., $341 \mathrm{p}$.

Brunauer, S., Emmett, P.H., and Teller, E., 1938, Adsorption of gases in multimolecular layers: Journal of American Chemical Society, v. 60, p. 309-319.

Bunde, R.L., Rosentreter, J.J., and Liszewski, M.J., 1998, Rate of strontium sorption and the effects of variable aqueous concentrations of sodium and potassium on strontium distribution coefficients of a surficial sediment at the Idaho National Engineering Laboratory, Idaho: Environmental Geology, v. 34(2/3), p. 135-142.

Bunde, R.L., Rosentreter, J.J., Liszewski, M.J., Hemming, C.H., and Welhan, J., 1997, Effects of calcium and magnesium on strontium distribution coefficients: Environmental Geology, v. 32(3), p. 219-229.
Colello, J.J., Rosentreter, J.J., Bartholomay, R.C., and Liszewski, M.J., 1998, Strontium distribution coefficients of basalt core samples from the Idaho National Engineering and Environmental Laboratory, Idaho: U.S. Geological Survey WaterResources Investigations Report 98-4256, 68 p.

Del Debbio, J.A., and Thomas, T.R., 1989, Transport properties of radionuclides and hazardous chemical species in soils at the Idaho Chemical Processing Plant: Idaho Falls, Idaho, Westinghouse Idaho Nuclear Company, Inc., WINCO-1068 [variously paged].

Eisenbud, M., 1973, Environmental radioactivity: New York and London, Academic Press, 542 p.

Fetter, C.W., 1993, Contaminant hydrogeology: New York, Macmillan International, $458 \mathrm{p}$.

Greenberg, A.E., Clesceri, L.S., and Eaton, A.D., eds., 1992, Standard Methods For the Examination of Water and Wastewater, 18th ed: American Public Health Association, American Water Works Association, Water Environment Federation [variously paged].

Hawkins, D.B., and Short, H.L., 1965, Equations for the sorption of cesium and strontium on soil and clinoptilolite: U.S. Atomic Energy Commission, Idaho Operations Office, IDO-12046, 33 p.

Hemming, C.H., Bunde, R.L., Liszewski, M.J., Rosentreter, J.J., and Welhan, J., 1997, Effect of experimental techniques on the determination of strontium distribution coefficients of a surficial sediment from the Idaho National Engineering Laboratory, Idaho: Water Research, v. 31, no. 7, p. 1629-1636.

Hower, J., and Mowatt, T.C., 1966, The mineralogy of illites and mixed-layer illite/montmorillonites: American Mineralogist, v. 51, p. 825-854.

Jackson, R.E., and Inch, K.J., 1983, Partitioning of strontium-90 among aqueous and mineral species in a contaminated aquifer: Environmental Science and Technology, v. 17, p. 231-237.

Kipp, K.L., Stollenwerk, K.G., and Grove, D.B., 1986, Groundwater transport of strontium-90 in a glacial outwash environment: Water Resources Research, v. 22 , p. $519-530$. 
Knobel, L.L., Bartholomay, R.C., and Orr, B.R., 1997, Preliminary delineation of natural geochemical reactions, Snake River Plain aquifer system, Idaho National Engineering Laboratory and vicinity, Idaho: U.S. Geological Survey Water-Resources Investigations Report 97-4093, 52 p.

Liszewski, M.J., Rosentreter, J.J., and Miller, K.E., 1997, Strontium distribution coefficients of surficial sediment samples from the Idaho National Engineering Laboratory, Idaho: U.S. Geological Survey Water-Resources Investigations Report 97 4044, 33 p.

Liszewski, M.J., Rosentreter, J.J., Miller, K.E., and Bartholomay, R.C., 1998, Strontium distribution coefficients of surficial and sedimentary interbed samples from the Idaho National Engineering and Environmental Laboratory, Idaho: U.S. Geological Survey Water-Resources Investigations Report 98-4073, $55 \mathrm{p}$.

Mundorff, M.J., Crosthwaite, E.G., and Kilburn, C., 1964, Ground water for irrigation in the Snake River Basin in Idaho: U.S. Geological Survey Water-Supply Paper 1654, 224 p.

Newman, M.E., Porro, I., Scott, R., Dunnivant, F.M., Goff, R.W., Blevins, M.D., Ince, S.M., Leyba, J.D., DeVol, T.A., Elzerman, A.W., and Fjeld, R.A., 1996, Evaluation of the mobility of Am, Cs, Co, Pu, $\mathrm{Sr}$, and $\mathrm{U}$ through INEL basalt and interbed materials: Summary report of the INEL / Clemson University Laboratory Studies, WAG 7-82, INEL-95/282, September 19.

Patterson, R.J., and Spoel, T., 1981, Laboratory measurements of strontium distribution coefficient, $\mathrm{K}_{\mathrm{d}}$, for sediments from a shallow sand aquifer: Water Resources Research, v. 17, p. 513-520.
Pittman, J.R., Jensen, R.G., and Fischer, P.R., 1988, Hydrologic conditions at the Idaho National Engineering Laboratory, 1982 to 1985: U.S. Geological Survey Water-Resources Investigations Report 89-4008, 73 p.

Reed, M.F., and Bartholomay, R.C., 1994, Mineralogy of selected sedimentary interbeds at or near the Idaho National Engineering Laboratory, Idaho: U.S. Geological Survey Open-File Report 94-374 (DOE/ID-22116), $19 \mathrm{p}$.

Robertson, J.B., Schoen, R., and Barraclough, J.T., 1974, The influence of liquid waste disposal on the geochemistry of water at the National Reactor Testing Station, Idaho, 1952-1970: U.S. Geological Survey Open-File Report IDO-22053, 231 p.

Schmalz, B.L., 1972, Radionuclide distribution in soil mantle of the lithosphere as a consequence of waste disposal at the National Reactor Testing Station: U.S. Atomic Energy Commission, Idaho Operations Office, IDO-10049, $80 \mathrm{p}$.

Skougstad, M.W., Fishman, M.J., Friedman, L.C., Erdmann, D.E., and Duncan, S.S., eds., 1979, Methods for analysis of inorganic substances in water and fluvial sediment: U.S. Geological Survey Techniques of Water-Resources Investigations, book 5 , chap. A1, $626 \mathrm{p}$.

Sposito, G., 1989, The chemistry of soils: New York, Oxford University Press, $277 \mathrm{p}$.

U.S. Environmental Protection Agency, 1989, Protection of Environment, Code of Federal Regulations 40, Parts 100-149: Office of the Federal Register, National Archives and Records Administration, $948 \mathrm{p}$.

van Olphen, H., 1979, Data handbook for clay materials and other non-metallic minerals: Pergamon Press [variously paged]. 


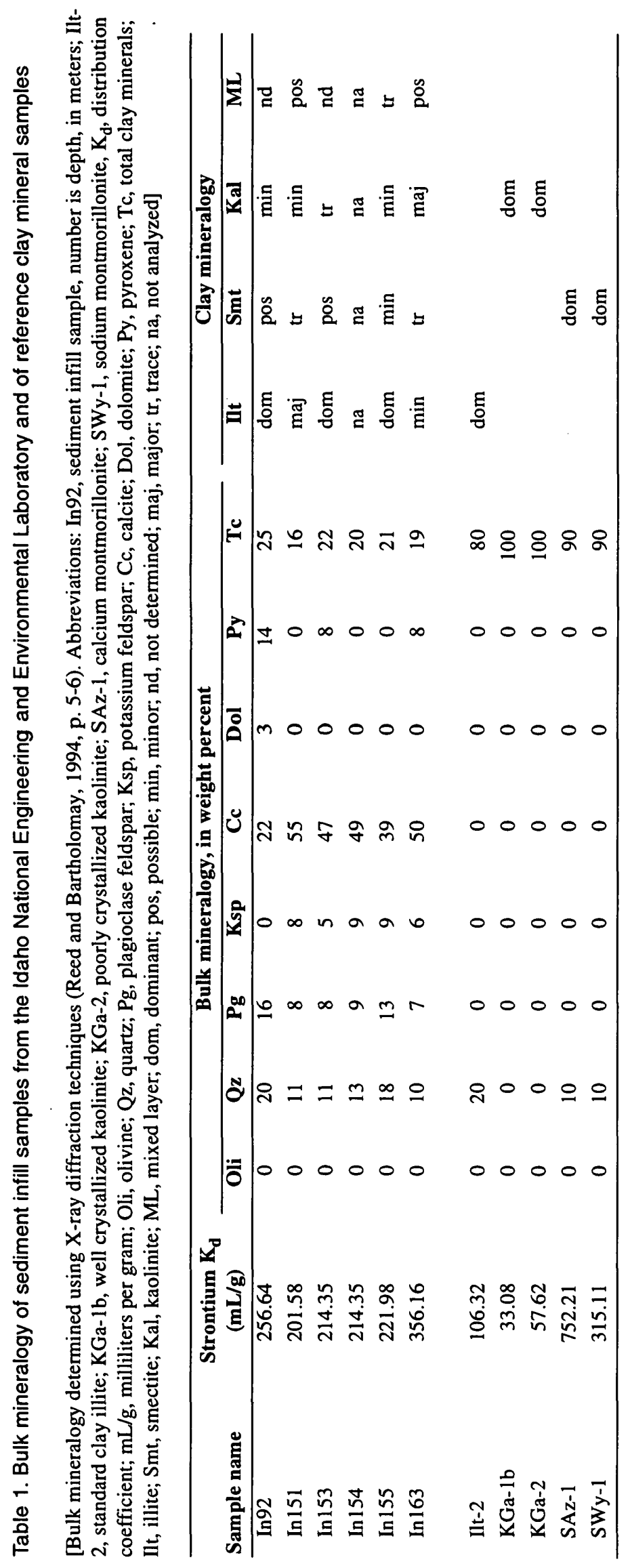


Table 2. Brunauer-Emmett-Teller surface-area analysis of selected samples used in batch experiments

[Abbreviations: $\mathrm{m}^{2} / \mathrm{g}$, square meters per gram of sample; $\mathrm{Sr} \mathrm{K}_{\mathrm{d}}$, strontium distribution coefficient; Ba92, basalt sample and depth in meters; In92, sediment infill sample and depth, in meters; Ilt-2, standard clay illite; KGa-1b, well crystallized kaolinite; KGa-2, poorly crystallized kaolinite; SAz-1, calcium montmorillonite; SWy-1, sodium montmorillonite; NR, not reported (Hower and Mowatt, 1966; van Olphen, 1979)]

\begin{tabular}{lcc}
\hline $\begin{array}{c}\text { Sample } \\
\text { name }\end{array}$ & Surface area $\left(\mathbf{m}^{2} / \mathbf{g}\right)$ & Sr $\mathbf{K}_{\mathbf{d}}$ \\
\hline Ba92 & 0.2933 & $4.3 \pm 9.9$ \\
Ba151 & .4694 & $9.3 \pm 9.8$ \\
Ba153 & .2276 & $1.5 \pm 3.3$ \\
Ba156 & .3603 & $1.7 \pm 7.0$ \\
Ba158 & .1916 & $1.3 \pm 8.4$ \\
Ba172 & .2306 & $3.9 \pm 6.9$ \\
& & \\
In92 & 12.3547 & $256.6 \pm 14.9$ \\
In151 & 12.5098 & $201.6 \pm 10.8$ \\
In153 & 18.7852 & $214.4 \pm 17.7$ \\
In155 & 20.6519 & $222.0 \pm 15.3$ \\
In163 & 15.3456 & $356.2 \pm 8.4$ \\
& & \\
Ilt-2 & $\mathrm{NR}$ & $106.3 \pm 10.2$ \\
KGa-1b & 10.05 & $33.1 \pm 4.9$ \\
KGa-2 & 23.50 & $57.6 \pm 8.6$ \\
SAz-1 & 97.42 & $752.2 \pm 21.4$ \\
SWy-1 & 31.80 & $315.1 \pm 23.0$ \\
\hline
\end{tabular}




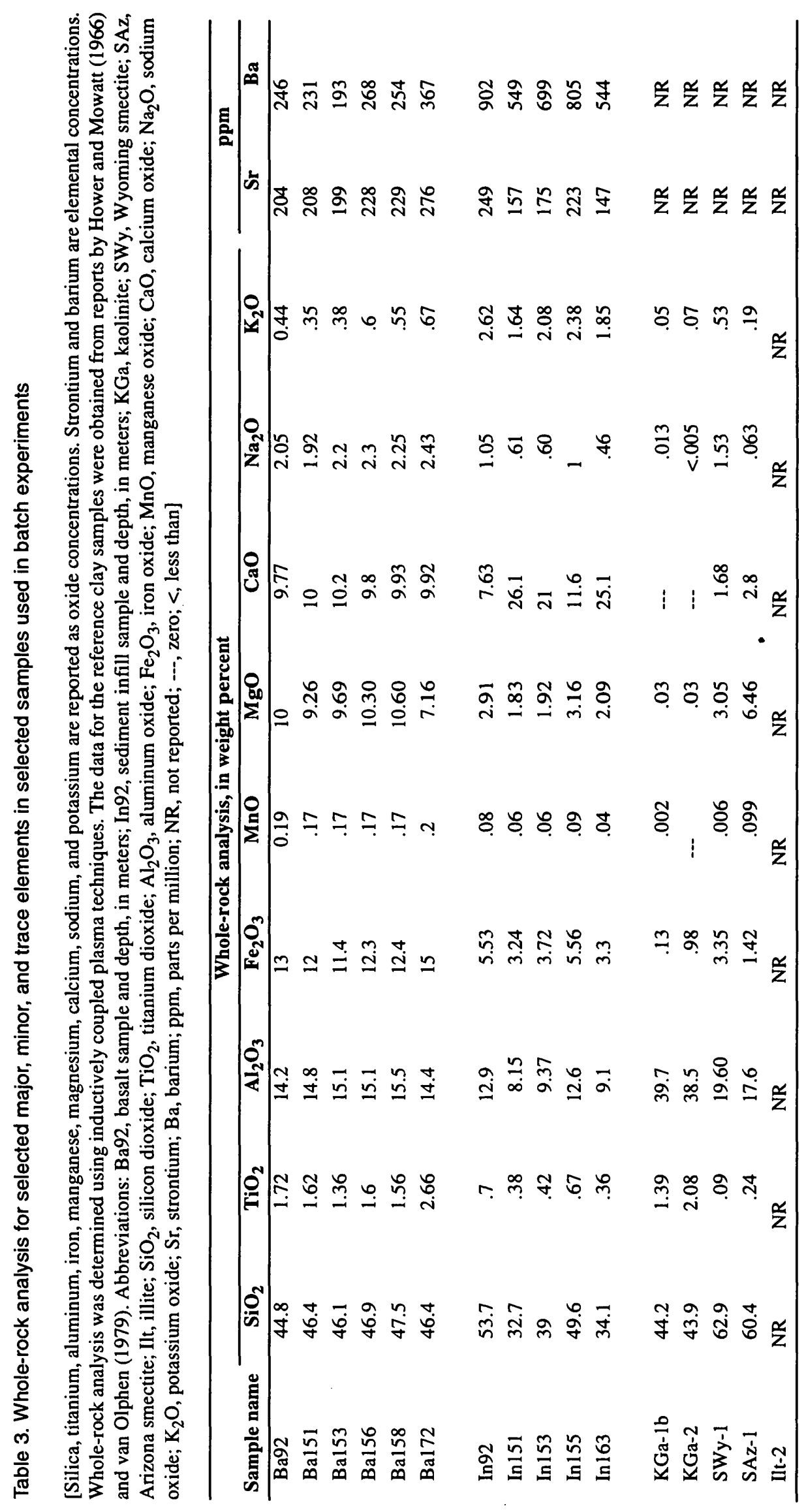




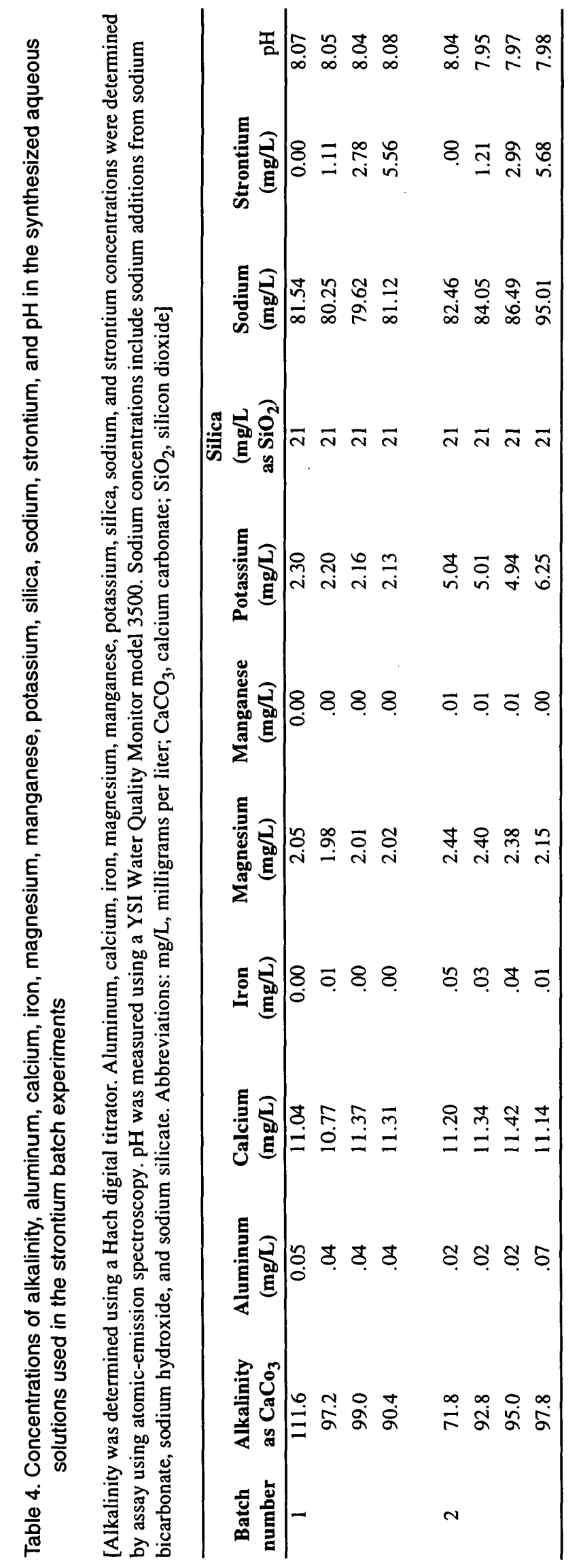


Table 5. Concentrations of alkalinity, calcium, magnesium, potassium, silica, sodium, and strontium, and pH in samples collected from waste-disposal ponds at the Idaho Nuclear Technology and Engineering Center

[Analyses were performed by the U.S. Geological Survey's National Water Quality Laboratory using analytical techniques prescribed by Skougstad and others (1979). Abbreviations: $\mathrm{mg} / \mathrm{L}$, milligrams per liter; $\mathrm{CaCO}_{3}$, calcium carbonate; $\mathrm{SiO}_{2}$, silicon dioxide. Location of ponds shown on fig. 2]

\begin{tabular}{lcccccccc}
\hline Date sampled & $\left.\begin{array}{c}\text { Alkalinity } \\
(\mathbf{m g} / \mathbf{L} \text { as } \\
\mathbf{C a C O}\end{array}\right)$ & $\begin{array}{c}\text { Calcium } \\
(\mathbf{m g} / \mathbf{L})\end{array}$ & $\begin{array}{c}\text { Magnesium } \\
(\mathbf{m g} / \mathbf{L})\end{array}$ & $\begin{array}{c}\text { Potassium } \\
(\mathbf{m g} / \mathbf{L})\end{array}$ & $\begin{array}{c}\text { Silica } \\
(\mathbf{m g} / \mathbf{L} \text { as SiO })\end{array}$ & $\begin{array}{c}\text { Sodium } \\
(\mathbf{m g} / \mathbf{L})\end{array}$ & $\begin{array}{c}\text { Strontium } \\
(\mathbf{m g} / \mathbf{L})\end{array}$ & \begin{tabular}{c} 
pH \\
\hline $10 / 27 / 86$
\end{tabular} \\
158 & 3.7 & 1.2 & 1.2 & 21 & 87 & 0.017 & 8.30 \\
$1 / 28 / 87$ & 159 & 5.7 & 1.4 & 2.5 & 21 & 84 & .029 & 8.29 \\
$10 / 26 / 87$ & 150 & 9.7 & 2.5 & 1.6 & 21 & 88 & .051 & 8.50 \\
$1 / 25 / 88$ & 125 & 2.5 & .65 & .90 & 24 & 87 & .012 & 8.00 \\
$4 / 26 / 88$ & 103 & 67 & 29 & 2.8 & 21 & 92 & .34 & 7.20 \\
$7 / 28 / 88$ & 137 & 260 & 53 & 1.5 & 24 & 340 & 1.3 & 8.00 \\
$10 / 31 / 88$ & 145 & 11 & 3.0 & 1.1 & 22 & 98 & .057 & 8.00 \\
\hline
\end{tabular}


Table 6. Calculated and measured strontium distribution coefficients of basalt samples from the Idaho National Engineering and Environmental Laboratory

[Calculated $K_{d} s$ are the slope of the linear isotherms; uncertainties are the standard error of the linear regression. Measured $K_{d} s$ are the average of three replicate determinations reported to the largest whole number; uncertainties for measured $\mathrm{K}_{\mathrm{d}} \mathrm{s}$ are the standard deviation of three replicate determinations. Abbreviations: Ba92, basalt sample and depth, in meters; $\mathrm{K}_{\mathrm{d}}$, distribution coefficient; $\mathrm{mL} / \mathrm{g}$, milliliters per gram; $\mathrm{mg} / \mathrm{L}$, milligrams per liter]

\begin{tabular}{|c|c|c|c|}
\hline Sample name & $\begin{array}{c}\text { Calculated } K_{d} \\
(\mathrm{~mL} / \mathrm{g})\end{array}$ & $\begin{array}{c}\text { Initial strontium } \\
\text { concentration }(\mathrm{mg} / \mathrm{L})\end{array}$ & $\begin{array}{l}\text { Measured } K_{d} \\
(\mathrm{~mL} / \mathrm{g})\end{array}$ \\
\hline \multirow[t]{4}{*}{ Ba92 } & $4.3 \pm 9.9$ & 0 & $-49.07 \pm 6.38$ \\
\hline & & 1 & $9.97 \pm 1.48$ \\
\hline & & 2.5 & $7.73 \pm 1.33$ \\
\hline & & 5 & $4.90 \pm 3.95$ \\
\hline \multirow[t]{4}{*}{ Bal51 } & $9.3 \pm 9.8$ & 0 & $-54.30 \pm 3.53$ \\
\hline & & 1 & $-2.23 \pm 0.94$ \\
\hline & & 2.5 & $5.04 \pm 4.36$ \\
\hline & & 5 & $8.74 \pm 2.76$ \\
\hline \multirow[t]{4}{*}{ Ba153 } & $1.5 \pm 3.3$ & 0 & $-37.39 \pm 5.81$ \\
\hline & & 1 & $1.19 \pm 1.87$ \\
\hline & & 2.5 & $3.50 \pm 0.87$ \\
\hline & & 5 & $1.27 \pm 0.24$ \\
\hline \multirow[t]{4}{*}{ Ba156 } & $1.7 \pm 7.0$ & 0 & $-53.62 \pm 7.52$ \\
\hline & & 1 & $6.71 \pm 0.82$ \\
\hline & & 2.5 & $7.11 \pm 0.31$ \\
\hline & & 5 & $1.92 \pm 2.02$ \\
\hline \multirow[t]{4}{*}{ Ba 158} & $1.3 \pm 8.4$ & 0 & $-48.05 \pm 2.52$ \\
\hline & & 1 & $-1.05 \pm 4.14$ \\
\hline & & 2.5 & $1.17 \pm 2.38$ \\
\hline & & 5 & $1.27 \pm 3.29$ \\
\hline \multirow[t]{4}{*}{ Ba172 } & $3.9 \pm 6.9$ & 0 & $-67.55 \pm 10.03$ \\
\hline & & 1 & $8.32 \pm 3.25$ \\
\hline & & 2.5 & $8.31 \pm 2.48$ \\
\hline & & 5 & $3.77 \pm 1.64$ \\
\hline
\end{tabular}



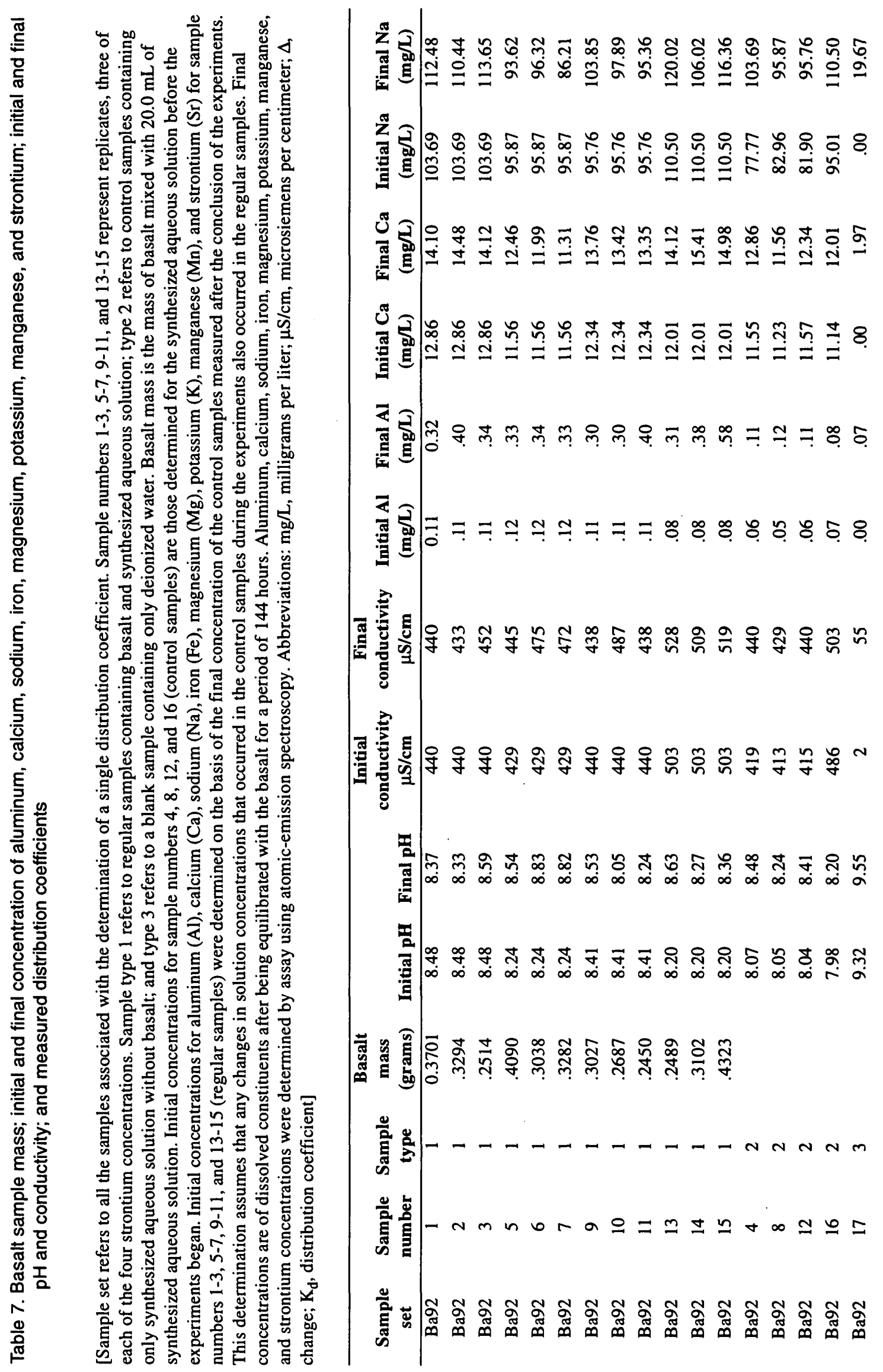


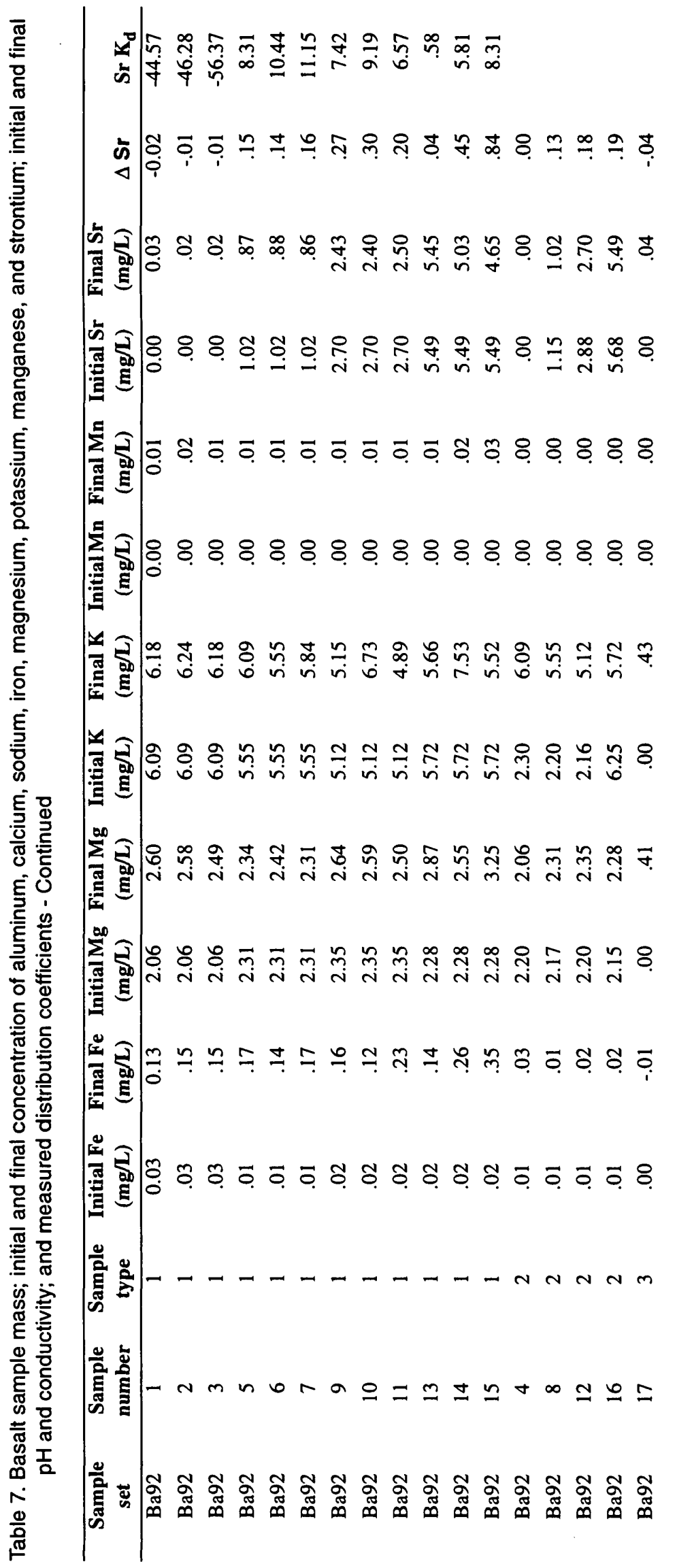




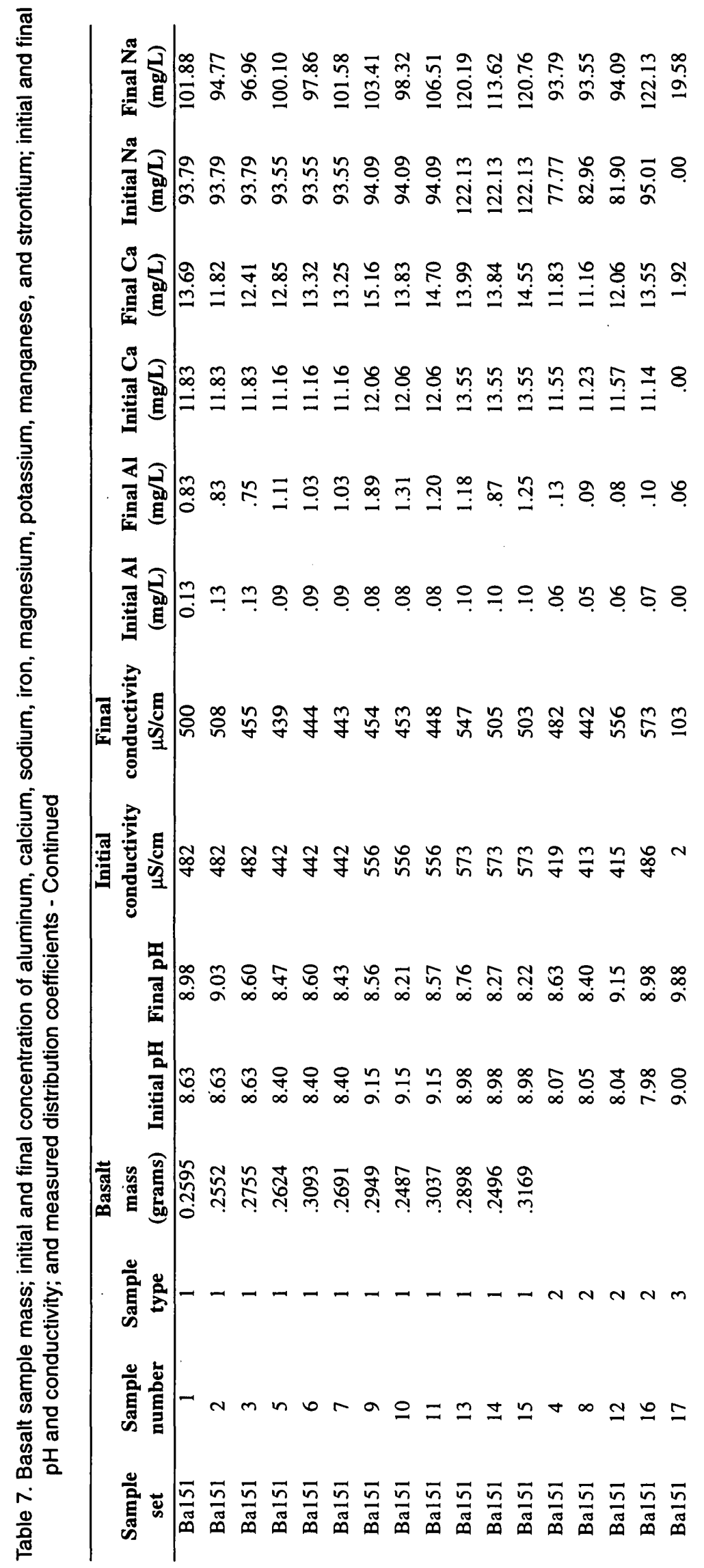




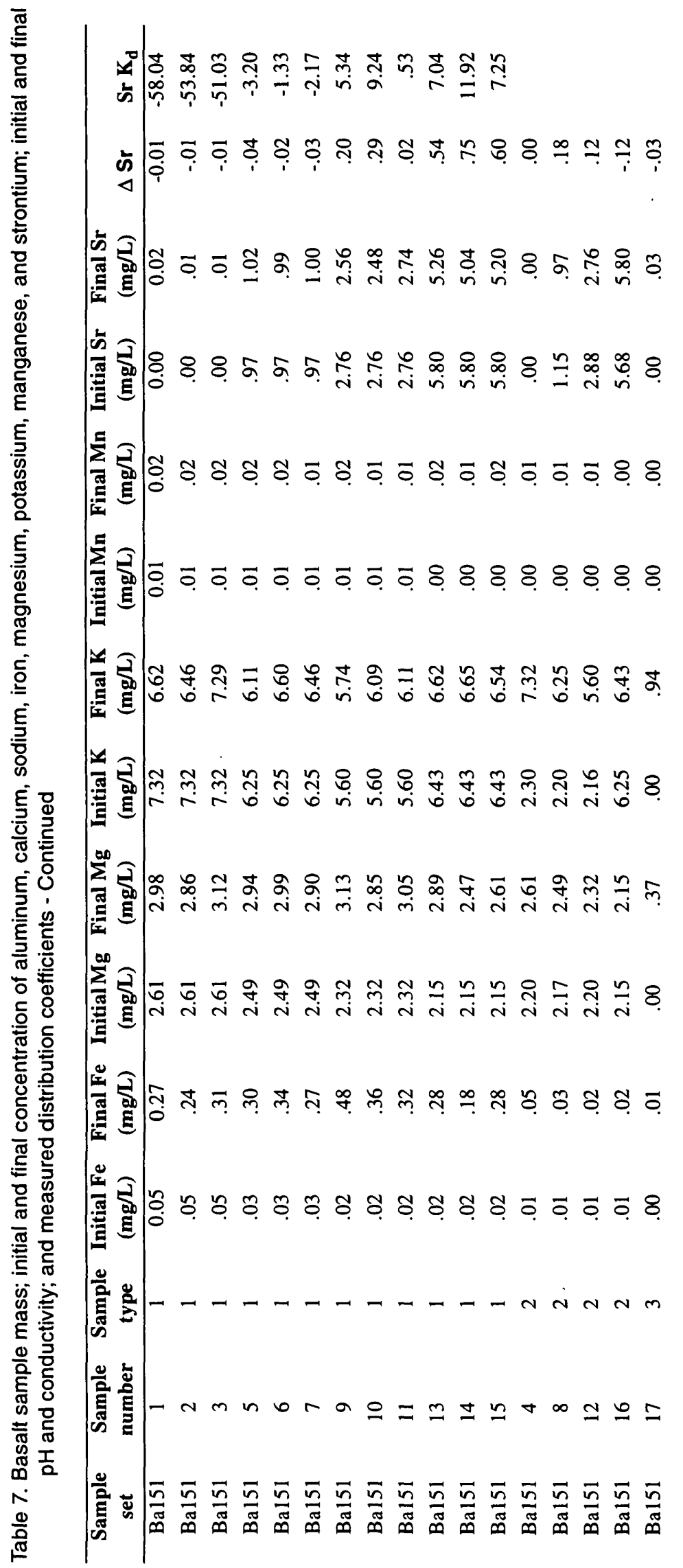




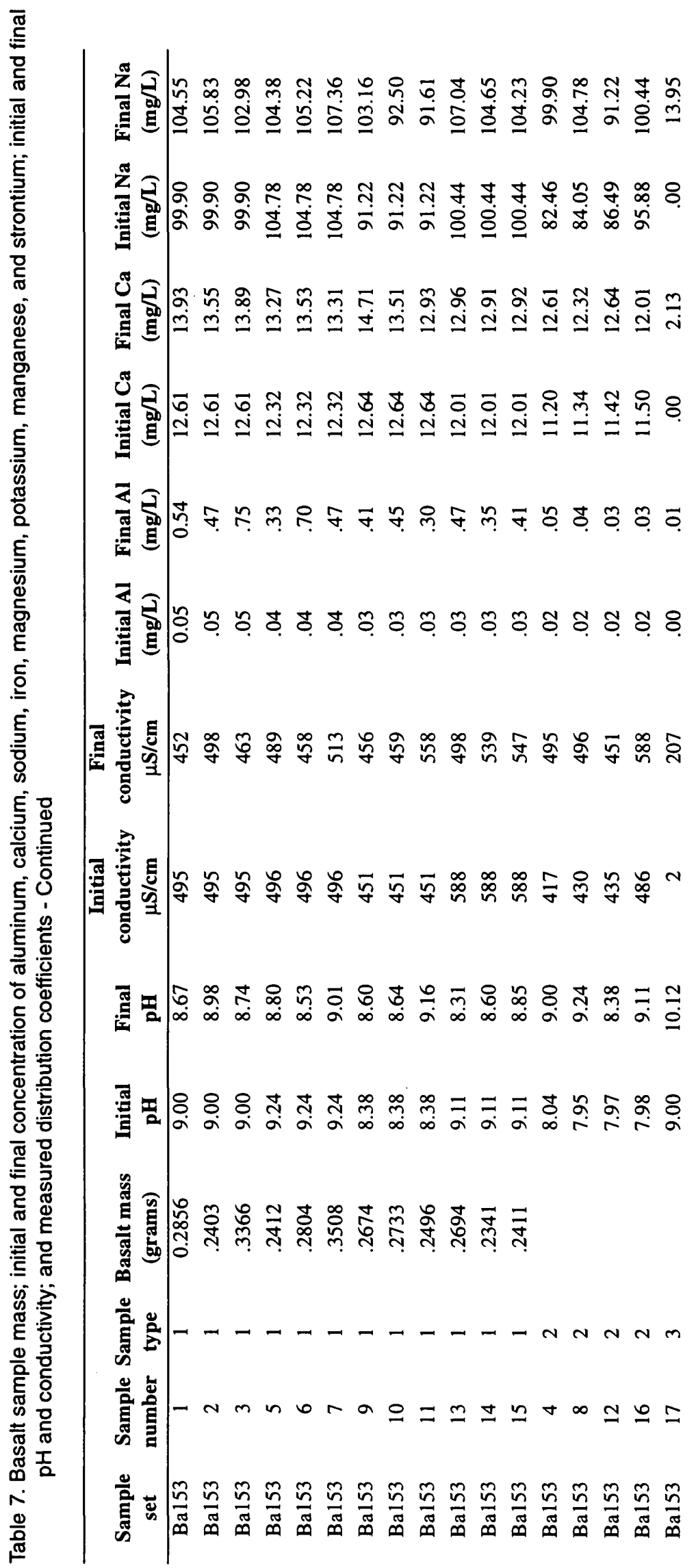




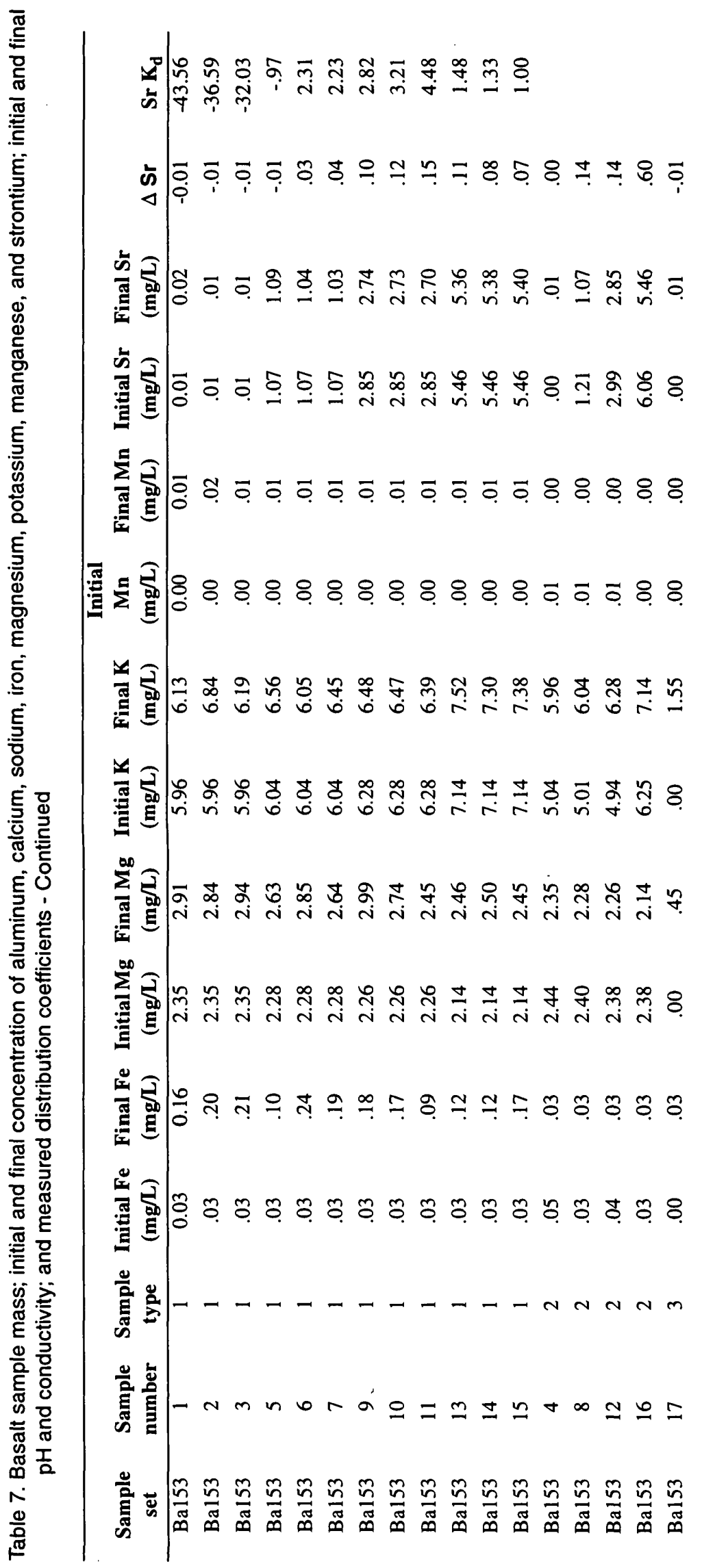




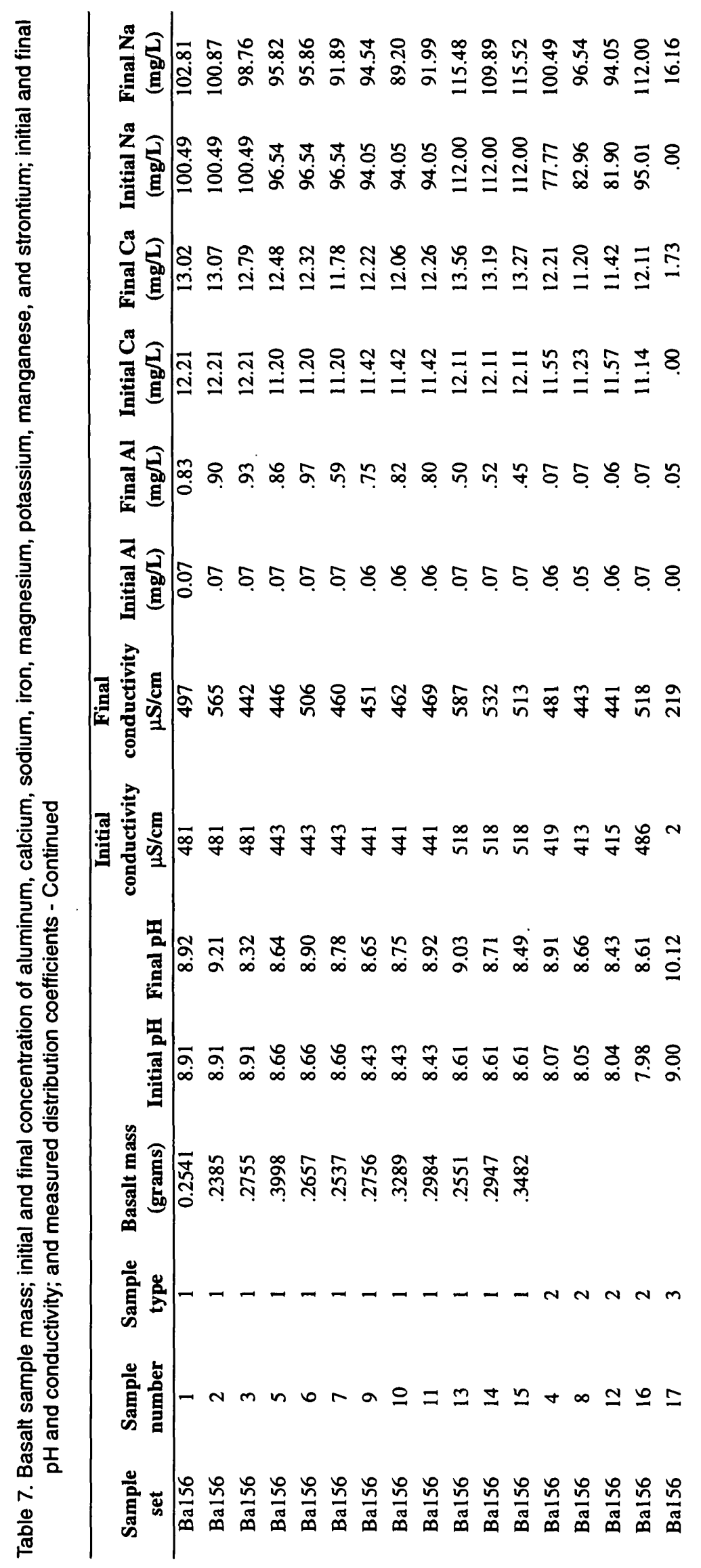




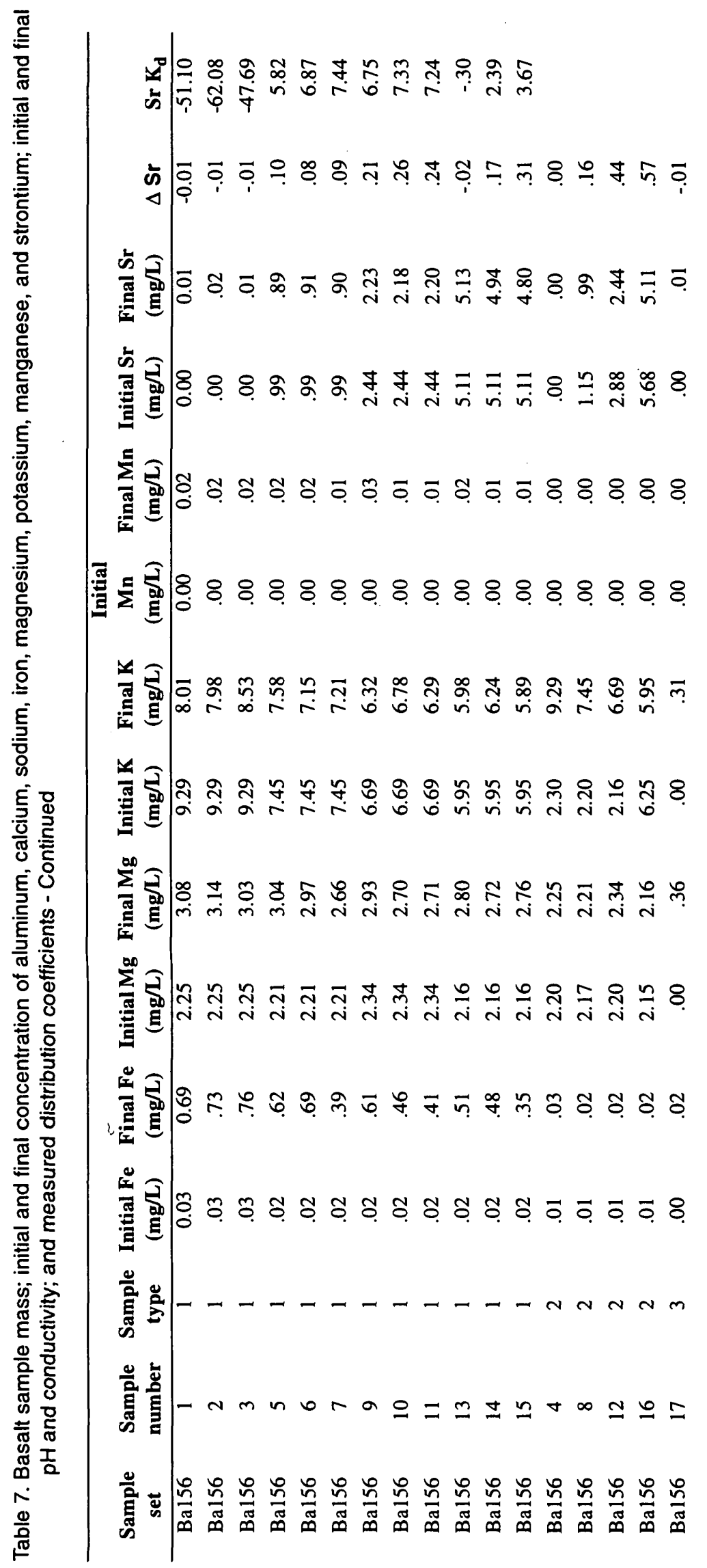




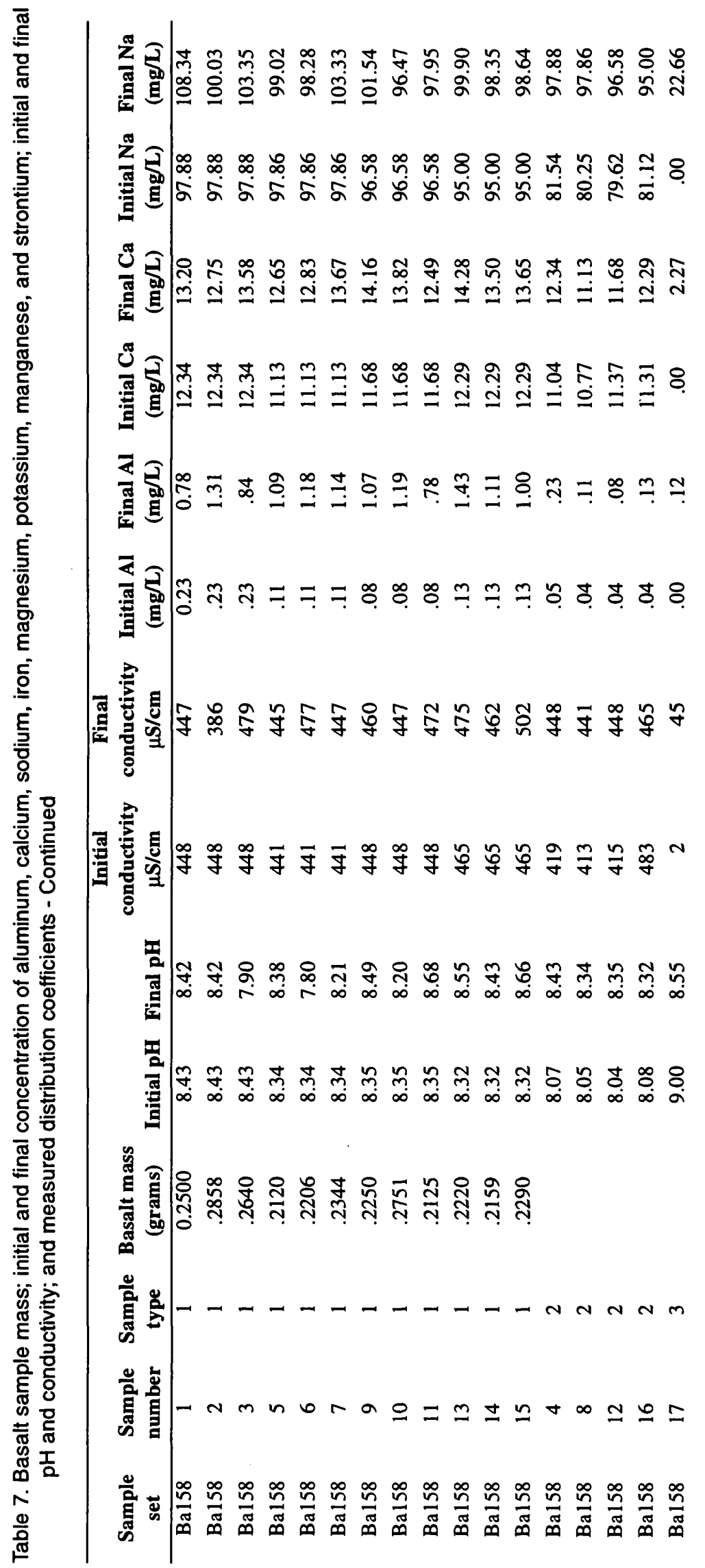




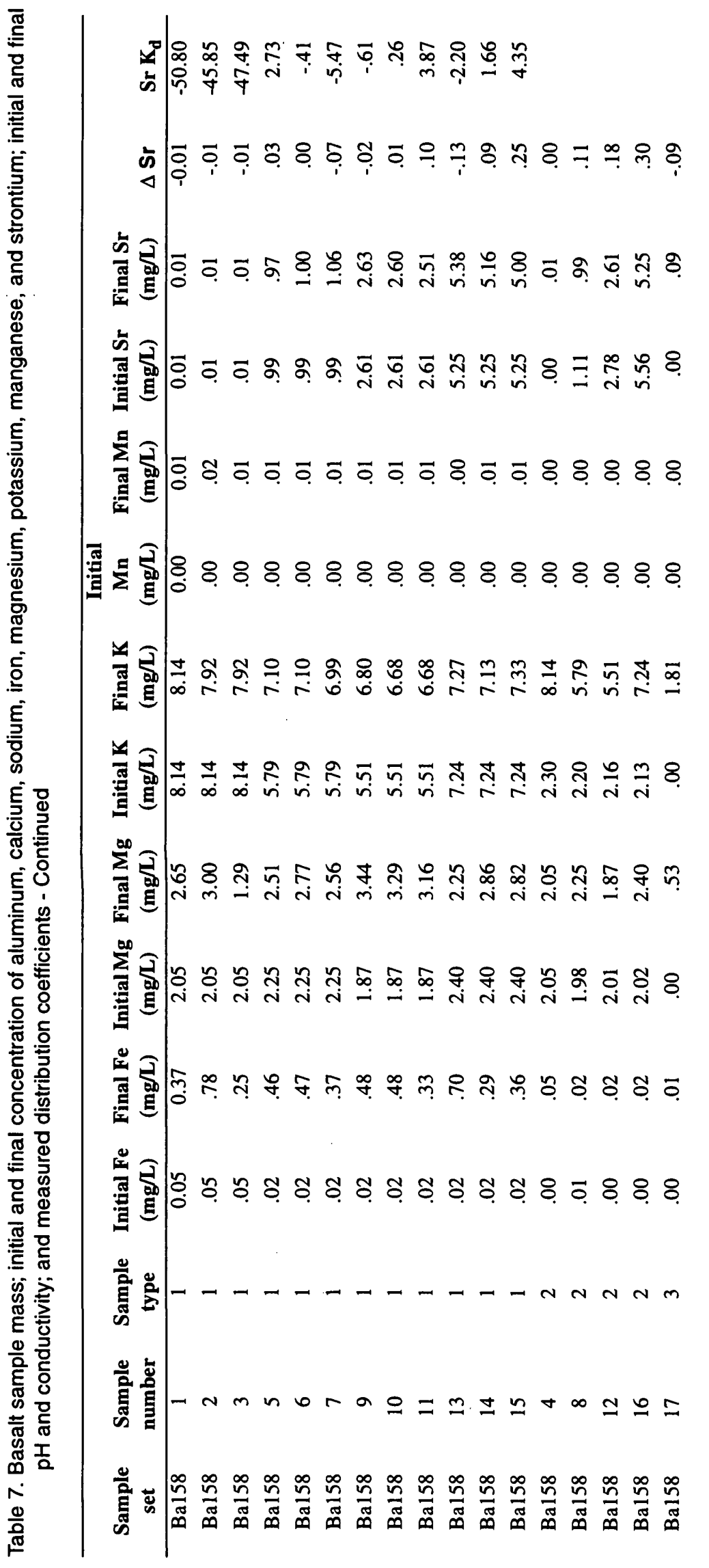




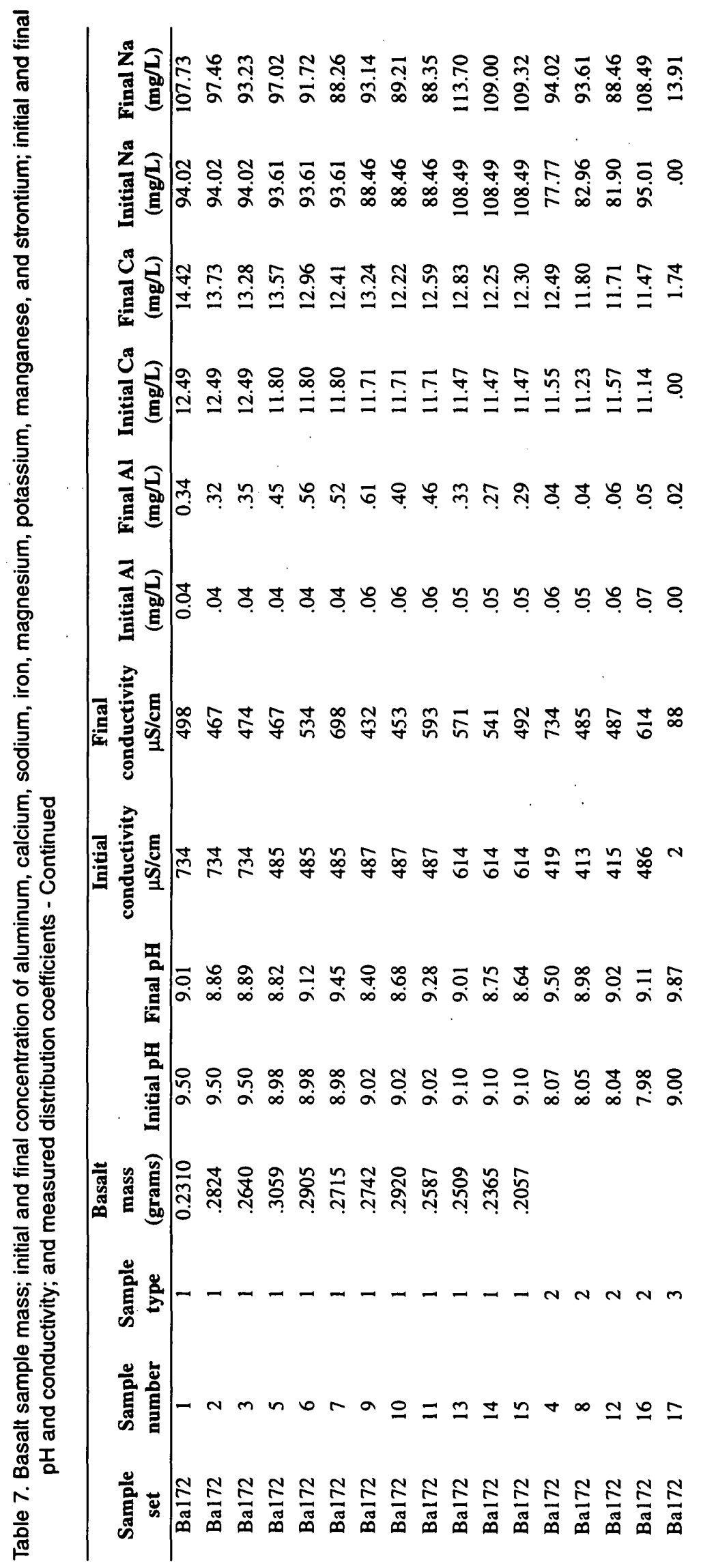




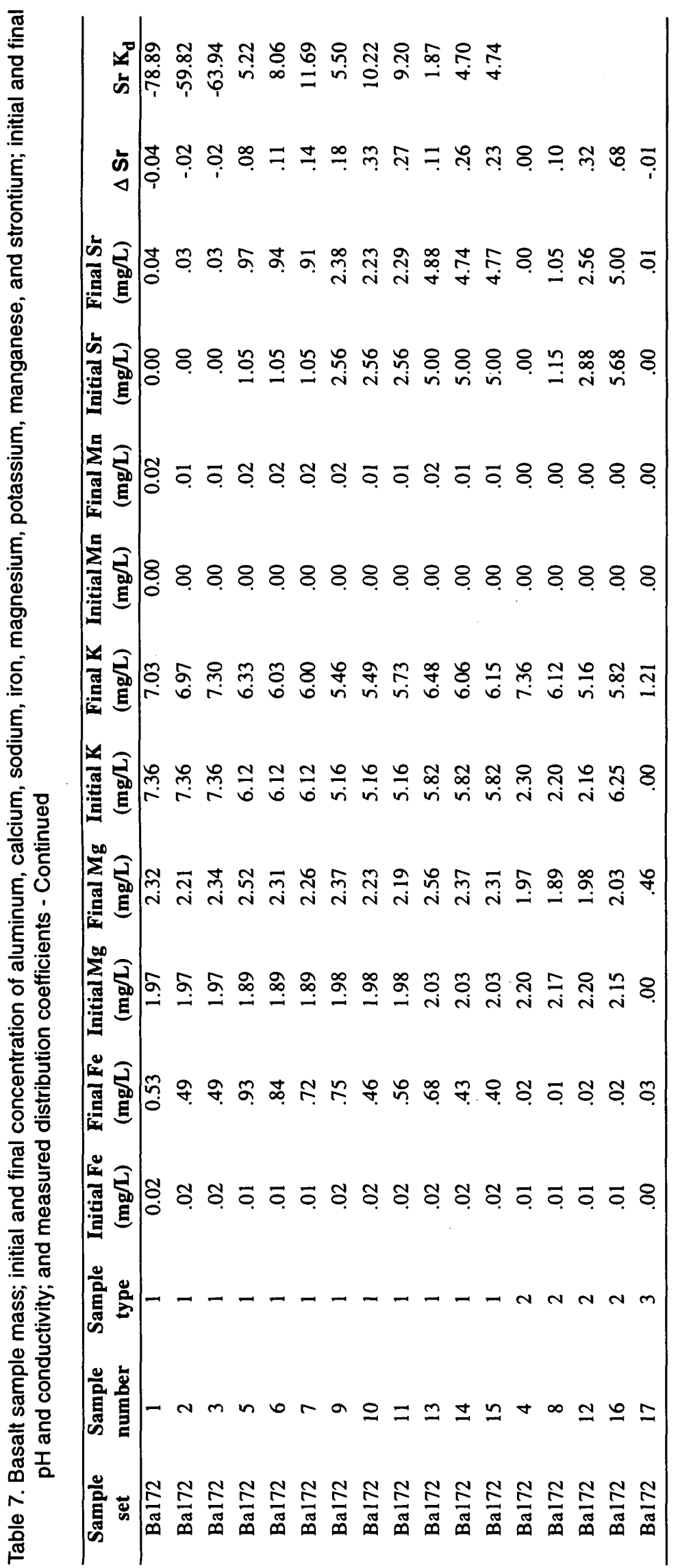


Table 8. Strontium distribution coefficients and standard error of basalt samples compared with previously analyzed basalt samples with sediment infill

[The first set of samples, analyzed for this study, were cleaned of all sediment infill. The second set of samples, analyzed previously, (Colello and others, 1998) contained sediment infill material. All basalt samples in this table were collected from core near the Idaho Nuclear Technology and Engineering Center. Abbreviations: Ba92, basalt sample and depth, in meters; number, for second set of basalt samples is depth, in meters; $\mathbf{K}_{d}$, strontium distribution coefficient; $\mathrm{mL} \mathbf{g}$, milliliters per gram]

\begin{tabular}{lcc}
\hline Sample name & $\mathbf{K}_{\mathbf{d}} \mathbf{( m \mathbf { L } / \mathbf { g } )}$ & Standard error \\
\hline Ba92 & 4.3 & 9.9 \\
Ba151 & 9.3 & 9.8 \\
Ba153 & 1.5 & 3.3 \\
Ba156 & 1.7 & 7.0 \\
Ba158 & 1.3 & 8.4 \\
Ba172 & 3.9 & 6.9 \\
& & \\
$14 \mathrm{a}$ & 13.4 & 1.5 \\
$14 \mathrm{~b}$ & 7.4 & .96 \\
64 & 10.7 & 1.2 \\
68 & 7.7 & 1.4 \\
130 & 3.6 & 1.3 \\
153 & 4.0 & .79 \\
156 & 4.4 & 1.0 \\
172 & 8.7 & 1.1 \\
189 & 4.1 & .95 \\
209 & 7.1 & 1.0 \\
$211 \mathrm{a}$ & 7.3 & 1.7 \\
$211 \mathrm{~b}$ & 7.8 & 1.1 \\
221 & 12.3 & 1.8 \\
\hline
\end{tabular}


Table 9. Calculated and measured strontium distribution coefficients of sediment infill samples from the Idaho National Engineering and Environmental Laboratory

[Calculated $K_{d} s$ are the slope of the linear isotherms; uncertainties are the standard error of the linear regression. Measured $K_{d} s$ are the average of three replicate determinations reported to the largest whole number; uncertainties for measured $K_{d} s$ are the standard deviation of three replicate determinations. Abbreviations: $I n 92$, sediment infill sample and depth, in meters; $K_{d}$, distribution coefficient; $\mathrm{mL} / \mathrm{g}$, milliliters per gram; mg/L, milligrams per liter]

\begin{tabular}{|c|c|c|c|}
\hline Sample name & $\begin{array}{c}\text { Calculated } \mathrm{K}_{\mathrm{d}} \\
(\mathrm{mL} / \mathrm{g})\end{array}$ & $\begin{array}{c}\text { Initial strontium } \\
\text { concentration }(\mathrm{mg} / \mathrm{L})\end{array}$ & $\begin{array}{l}\text { Measured } \mathrm{K}_{\mathrm{d}} \\
\quad(\mathrm{mL} / \mathrm{g})\end{array}$ \\
\hline \multirow[t]{4}{*}{ In92 } & $256.6 \pm 14.9$ & 0 & $-59.08 \pm 6.20$ \\
\hline & & 1. & $210.90 \pm 7.64$ \\
\hline & & 2.5 & $259.85 \pm 9.93$ \\
\hline & & 5 & $241.50 \pm 10.06$ \\
\hline \multirow[t]{4}{*}{ In 151} & $201.6 \pm 10.8$ & 0 & $-75.28 \pm 6.56$ \\
\hline & & 1 & $191.84 \pm 25.62$ \\
\hline & & 2.5 & $184.85 \pm 22.72$ \\
\hline & & 5 & $192.25 \pm 5.36$ \\
\hline \multirow[t]{4}{*}{ In153 } & $214.4 \pm 17.7$ & 0 & $-68.92 \pm 3.17$ \\
\hline & & 1 & $204.69 \pm 6.26$ \\
\hline & & 2.5 & $231.28 \pm 4.55$ \\
\hline & & 5 & $202.79 \pm 13.12$ \\
\hline \multirow[t]{4}{*}{ In155 } & $222.0 \pm 15.3$ & 0 & $-56.25 \pm 15.00$ \\
\hline & & 1 & $226.77 \pm 15.47$ \\
\hline & & 2.5 & $241.72 \pm 22.62$ \\
\hline & & 5 & $206.22 \pm 11.57$ \\
\hline \multirow[t]{4}{*}{ In 163} & $356.2 \pm 8.4$ & 0 & $-79.21 \pm 11.37$ \\
\hline & & 1 & $262.81 \pm 5.25$ \\
\hline & & 2.5 & $317.81 \pm 11.59$ \\
\hline & & 5 & $330.58 \pm 13.35$ \\
\hline
\end{tabular}




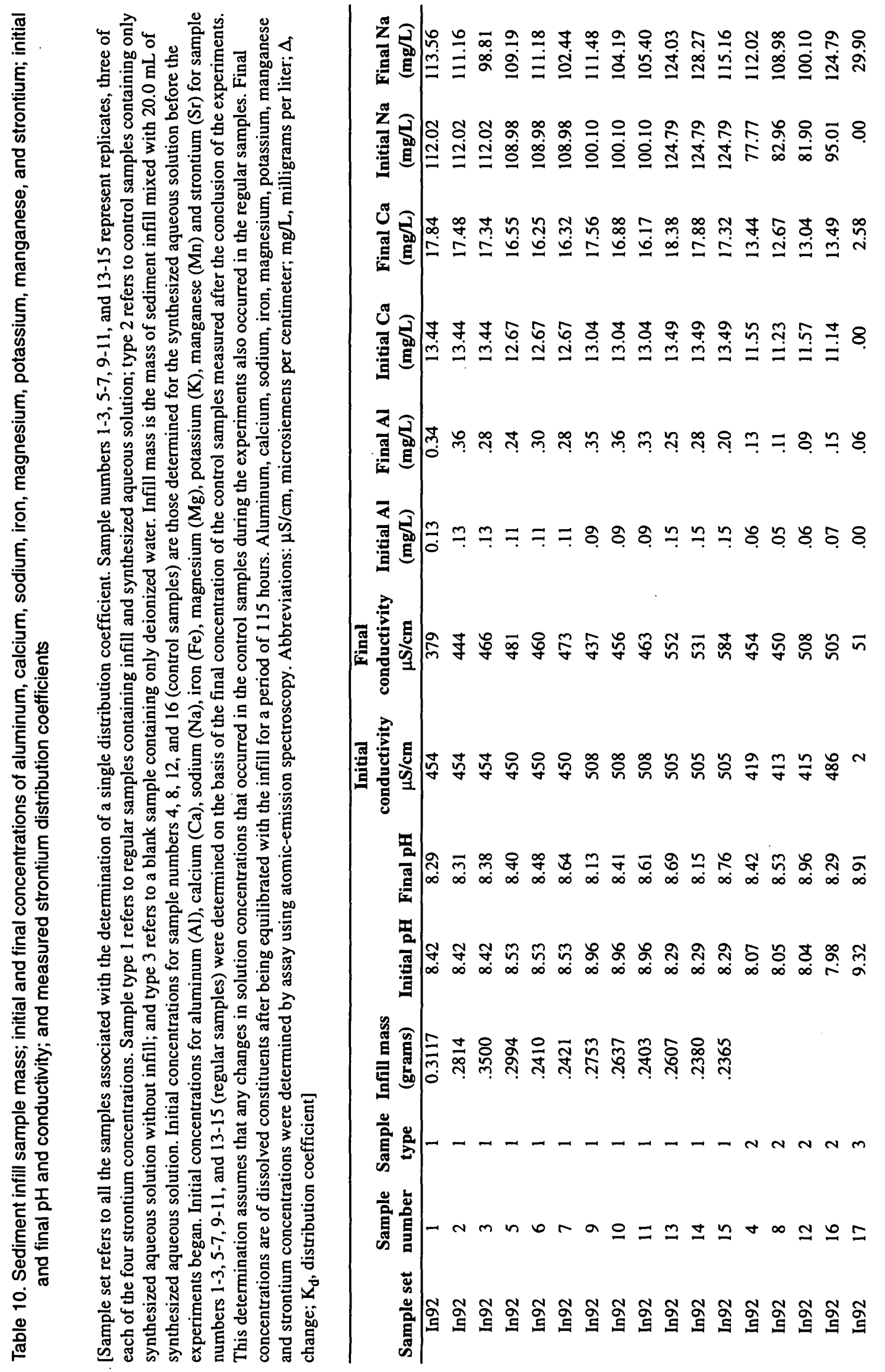




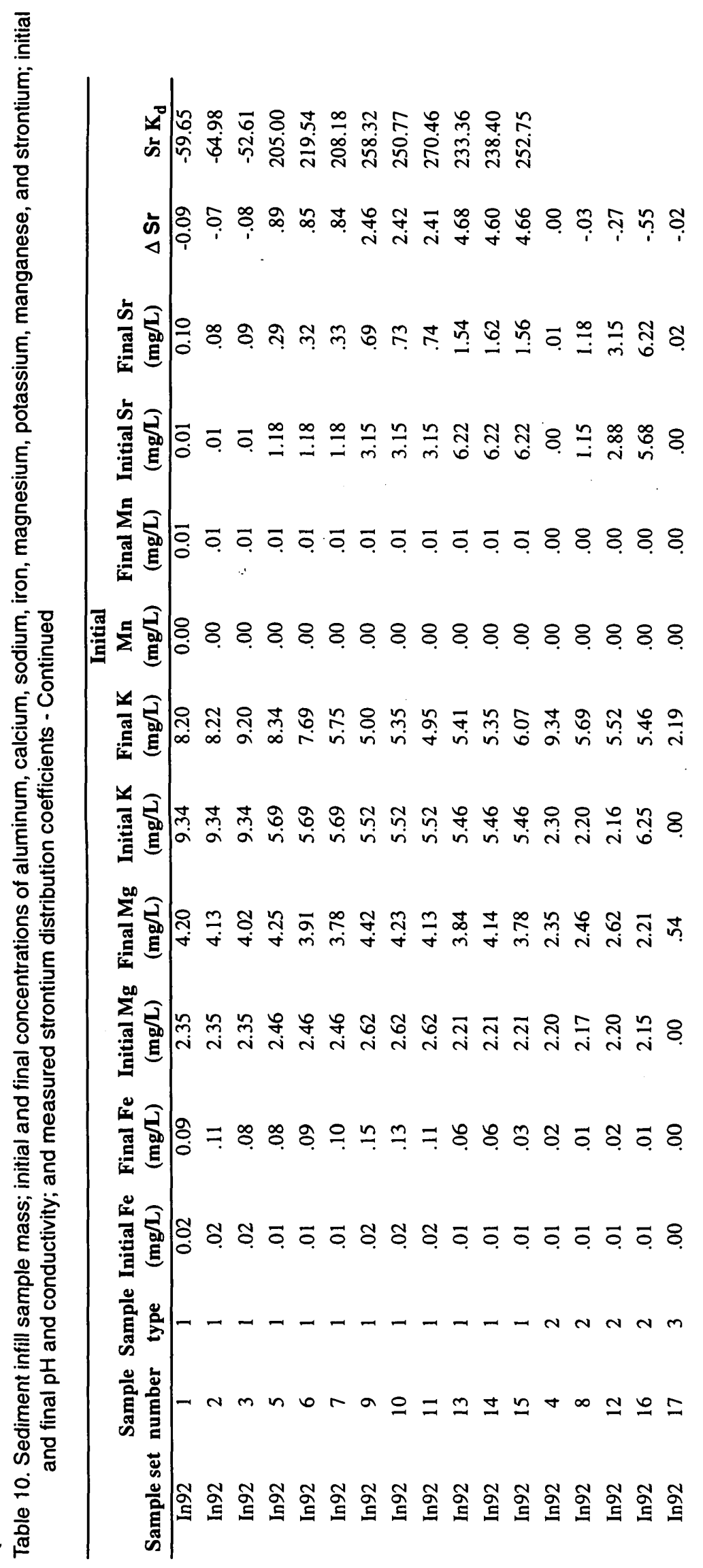




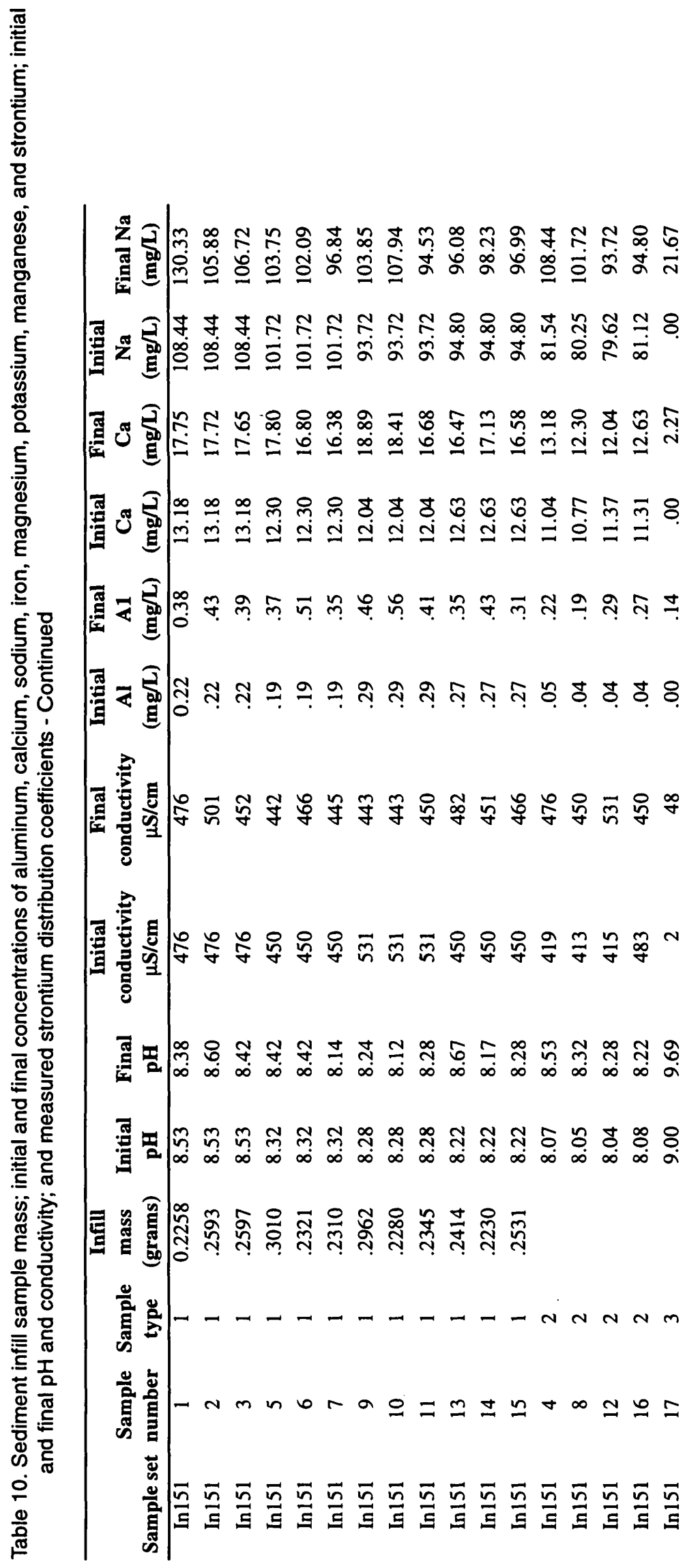




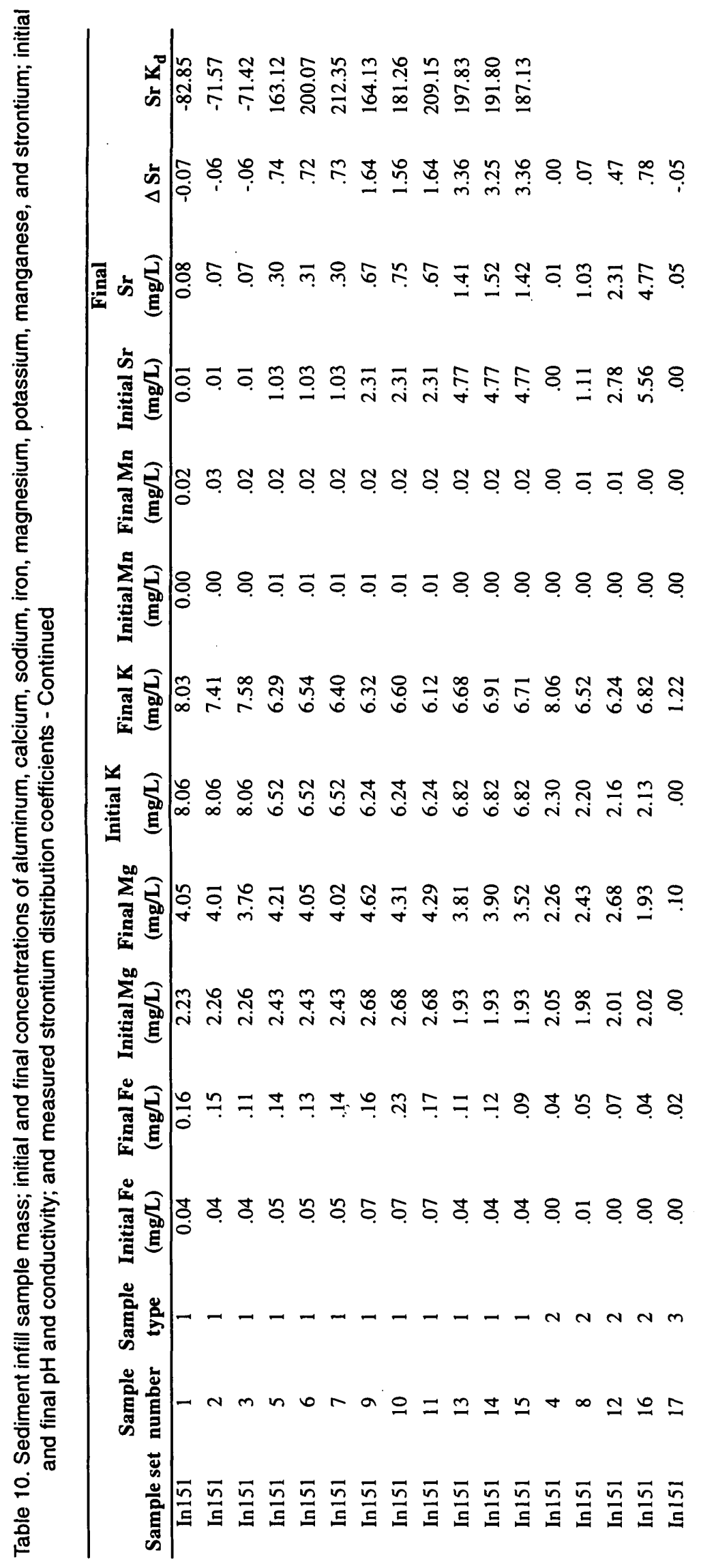




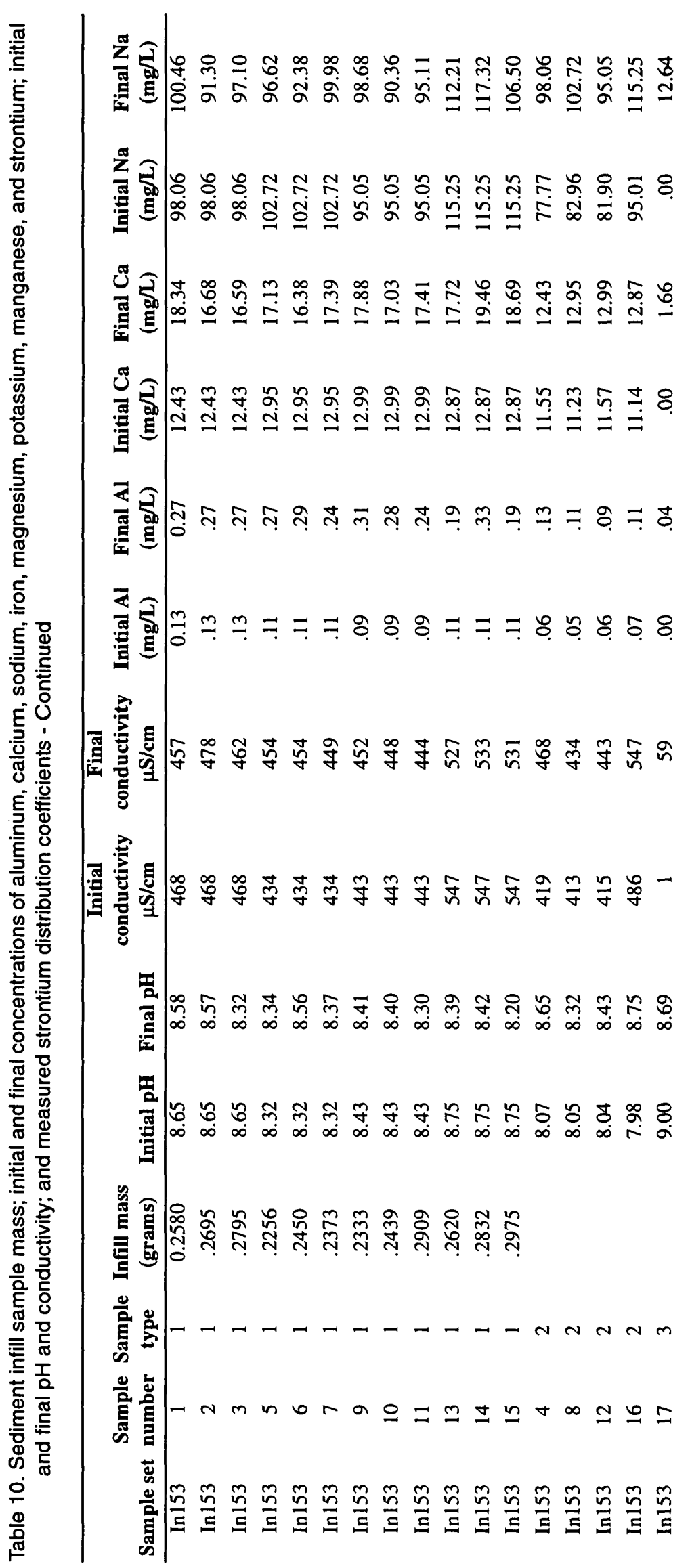




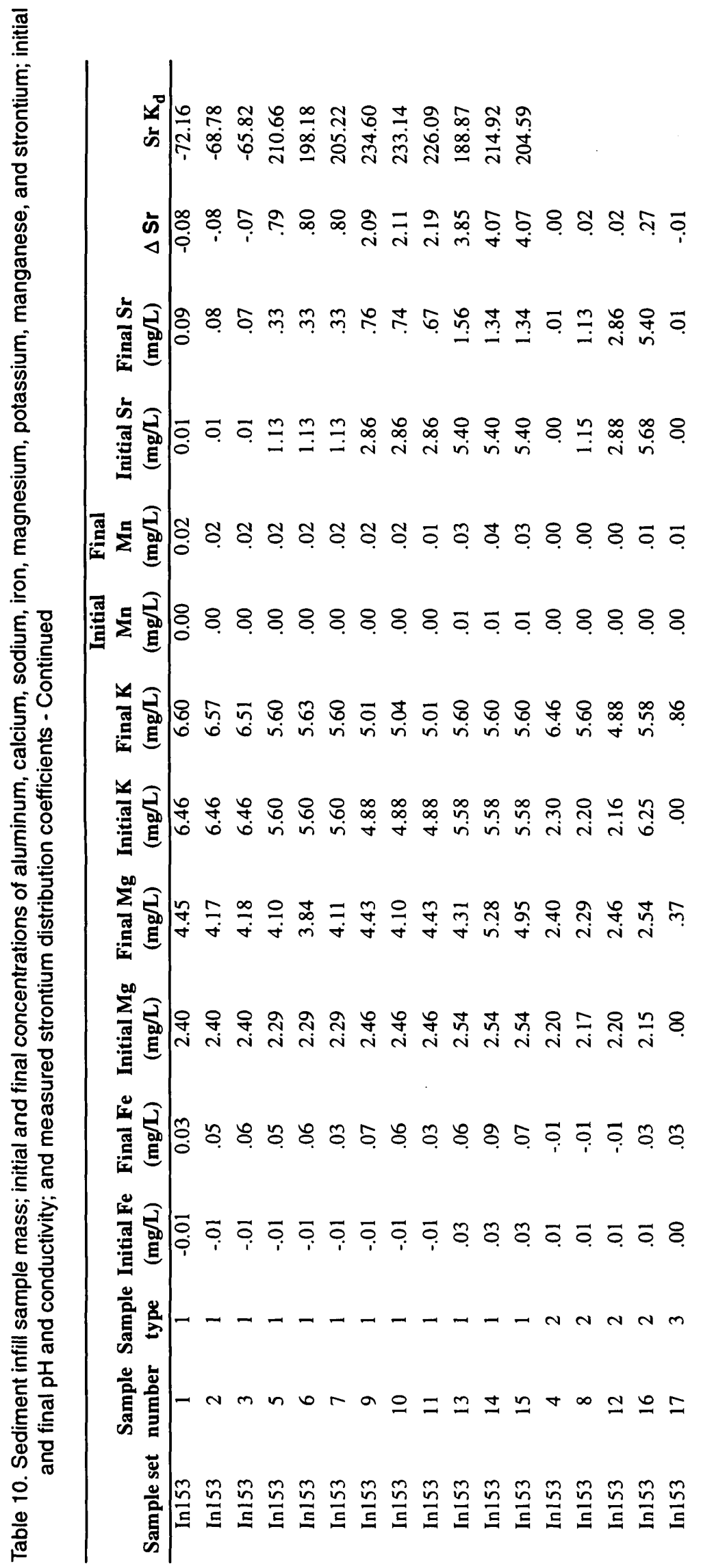




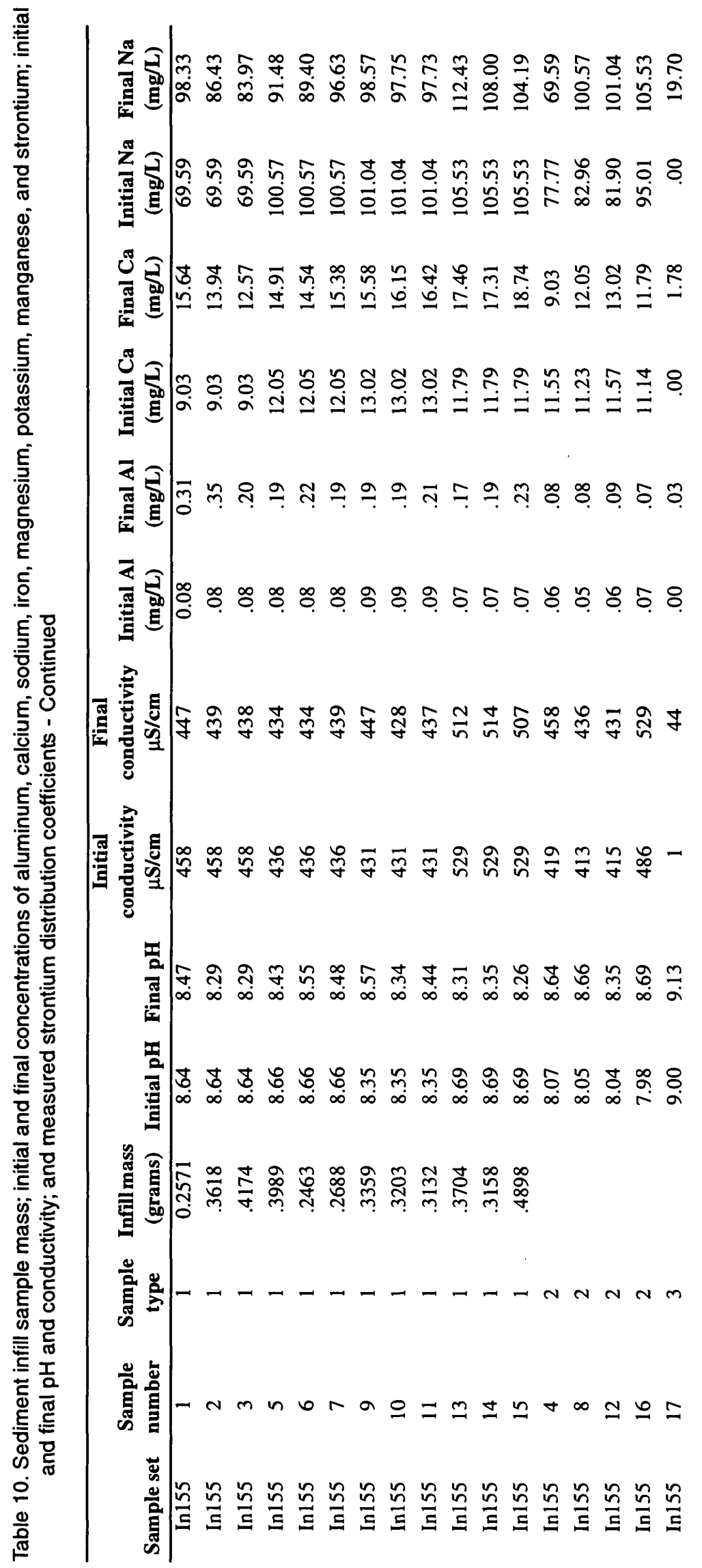




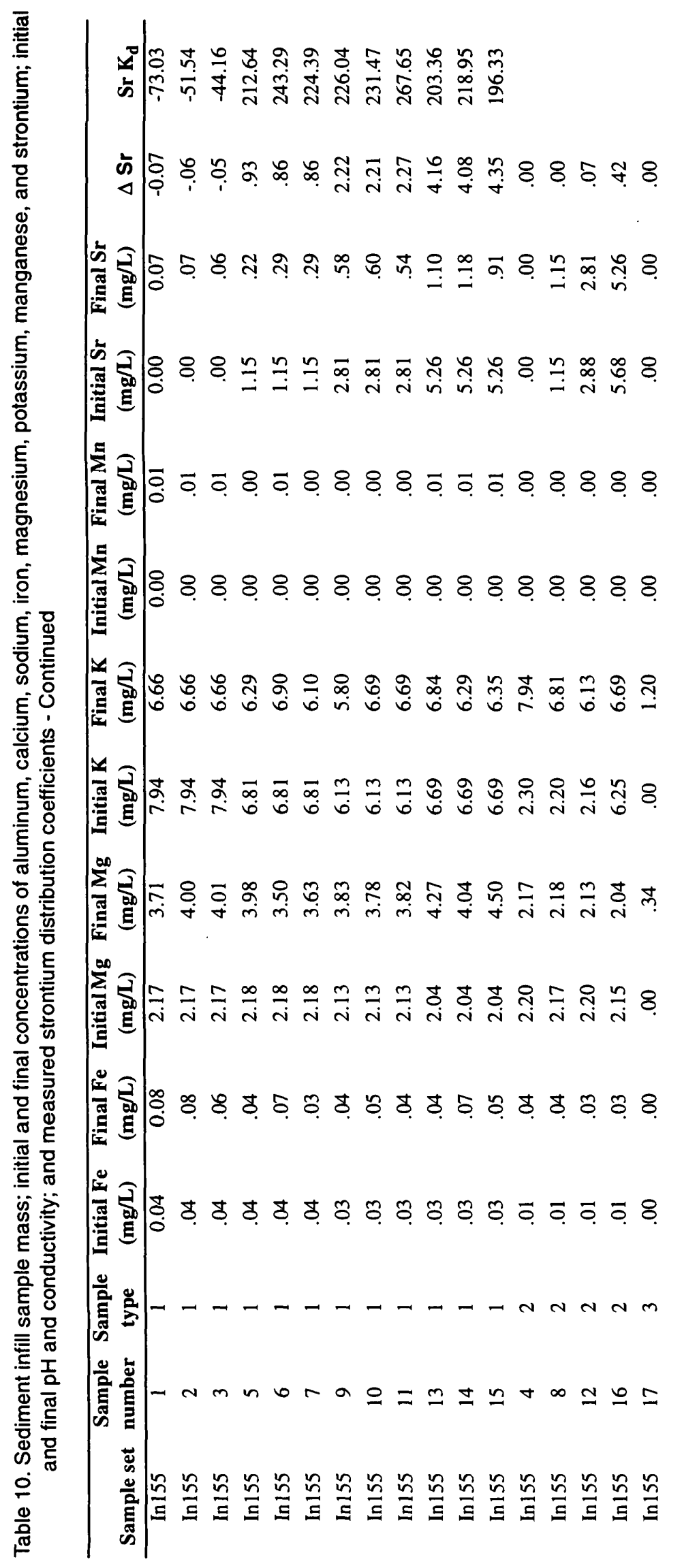




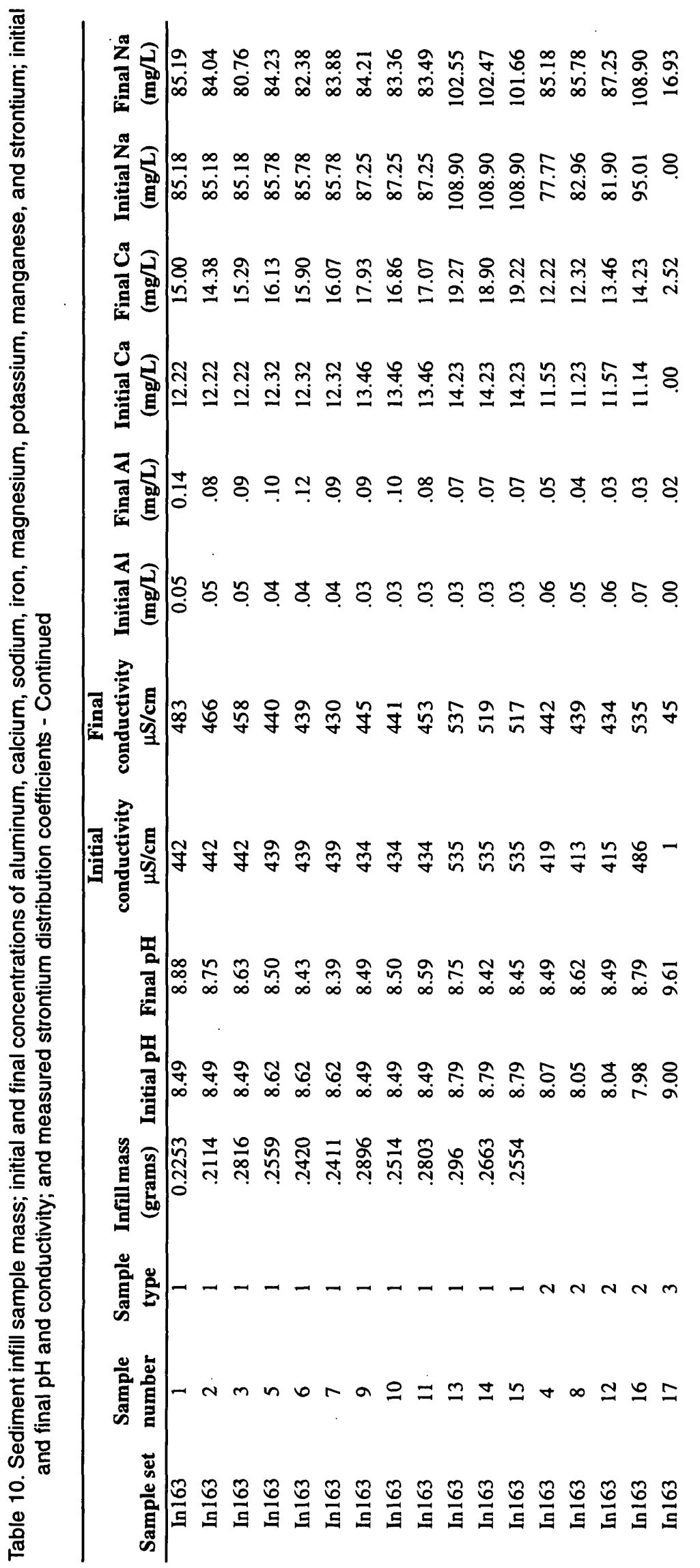




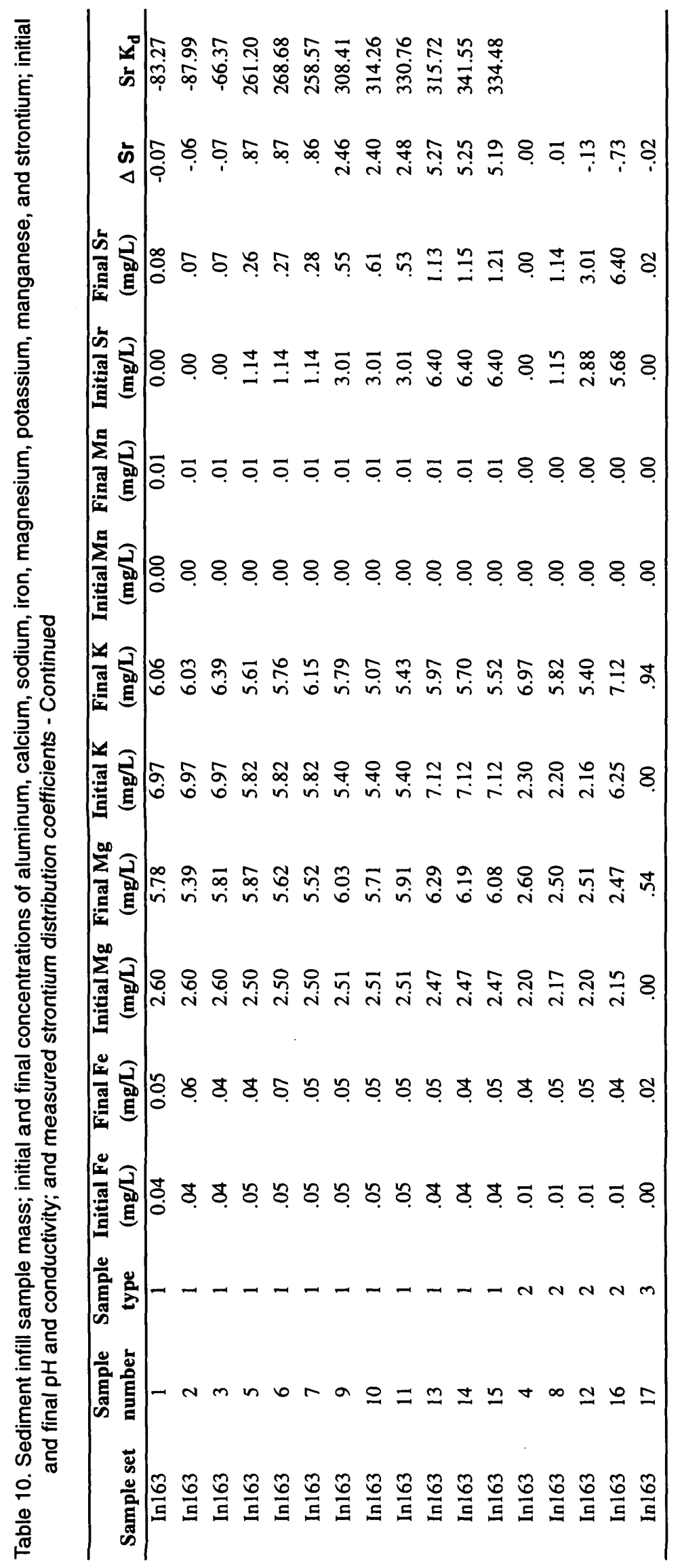


Table 11. Strontium distribution coefficients and standard errors for sediment infill samples and selected interbedded sediment samples

[The first set of samples, analyzed for this study, consisted of sediment that had filled vesicles and fractures in the basalt cores. The second set of samples, analyzed previously, were sediment interbed samples (Liszewski and others, 1998). All samples in this table were collected near the Idaho Nuclear Technology and Engineering Center. Abbreviations: In92, sediment infill sample and depth, in meters; IB1, interbed sample number; $K_{d}$, strontium distribution coefficient; $\mathrm{mL} / \mathrm{g}$, milliliters per gram]

\begin{tabular}{ccc}
\hline Sample name & $\mathbf{K}_{\mathbf{d}}(\mathbf{m L} / \mathbf{g})$ & Standard error \\
\hline In92 & 256.6 & 14.9 \\
In151 & 201.6 & 10.8 \\
In153 & 214.4 & 17.7 \\
In155 & 222.0 & 15.3 \\
In163 & 356.2 & 8.4 \\
& & \\
IB1 & 118.0 & 7.9 \\
IB2 & 225.6 & 14.6 \\
IB3 & 256.2 & 13.2 \\
IB4 & 46.5 & 3.7 \\
IB5 & 195.5 & 16.2 \\
IB6 & 157.2 & 11.4 \\
\hline
\end{tabular}


Table 12. Calculated and measured strontium distribution coefficients of standard material samples

[Calculated $K_{d} s$ are the slope of the linear isotherms; uncertainties are the standard error of the linear regression. Measured $K_{d} s$ are the average of three replicate determinations reported to the largest whole number; uncertainties for measured $\mathrm{K}_{\mathrm{d}} \mathrm{s}$ are the standard deviation of three replicate determinations. Abbreviations: $K_{d}$, distribution coefficient; $\mathrm{mL} / \mathrm{g}$, milliliters per gram; $\mathrm{mg} / \mathrm{L}$,

milligrams per liter; Ilt-2, standard clay illite; KGa-1b, well crystallized kaolinite; KGa-2, poorly crystallized kaolinite; SAz-1, calcium montmorillonite; SWy-1, sodium montmorillonite]

\begin{tabular}{|c|c|c|c|}
\hline Sample name & $\begin{array}{c}\text { Calculated } K_{d} \\
(\mathrm{~mL} / \mathrm{g})\end{array}$ & $\begin{array}{c}\text { Initial strontium } \\
\text { concentration }(\mathrm{mg} / \mathrm{L})\end{array}$ & $\begin{array}{c}\text { Measured } \mathrm{K}_{\mathrm{d}} \\
(\mathrm{mL} / \mathrm{g})\end{array}$ \\
\hline \multirow[t]{4}{*}{ Calcite } & $-2.6 \pm 5.8$ & 0 & $-36.65 \pm 7.97$ \\
\hline & & 1 & $4.00 \pm 3.65$ \\
\hline & & 2.5 & $1.50 \pm 0.72$ \\
\hline & & 5 & $-2.41 \pm 0.50$ \\
\hline \multirow[t]{4}{*}{ Ilt2 } & $106.3 \pm 10.2$ & 0 & $-48.48 \pm 4.29$ \\
\hline & & 1 & $99.72 \pm 7.00$ \\
\hline & & 2.5 & $110.85 \pm 8.05$ \\
\hline & & 5 & $104.10 \pm 7.52$ \\
\hline \multirow{4}{*}{$\mathrm{KGa}-1 \mathrm{~b}$} & $33.1 \pm 4.9$ & 0 & $-36.90 \pm 7.15$ \\
\hline & & 1 & $42.87 \pm 2.15$ \\
\hline & & 2.5 & $34.82 \pm 1.81$ \\
\hline & & 5 & $33.72 \pm 2.09$ \\
\hline \multirow[t]{4}{*}{$\mathrm{KGa}-2$} & $57.6 \pm 8.6$ & 0 & $-35.84 \pm 14.12$ \\
\hline & & 1 & $61.34 \pm 0.62$ \\
\hline & & 2.5 & $65.24 \pm 4.98$ \\
\hline & & 5 & $57.73 \pm 4.87$ \\
\hline \multirow[t]{4}{*}{ SAz-1 } & $752.2 \pm 21.4$ & 0 & $-77.27 \pm 10.04$ \\
\hline & & 1 & $123.05 \pm 34.06$ \\
\hline & & 2.5 & $299.54 \pm 30.21$ \\
\hline & & 5 & $440.26 \pm 8.06$ \\
\hline \multirow[t]{4}{*}{ SWy-1 } & $315.1 \pm 23.0$ & 0 & $-79.02 \pm 0.18$ \\
\hline & & 1 & $11.37 \pm 0.92$ \\
\hline & & 2.5 & $81.77 \pm 2.39$ \\
\hline & & 5 & $165.34 \pm 3.444$ \\
\hline
\end{tabular}



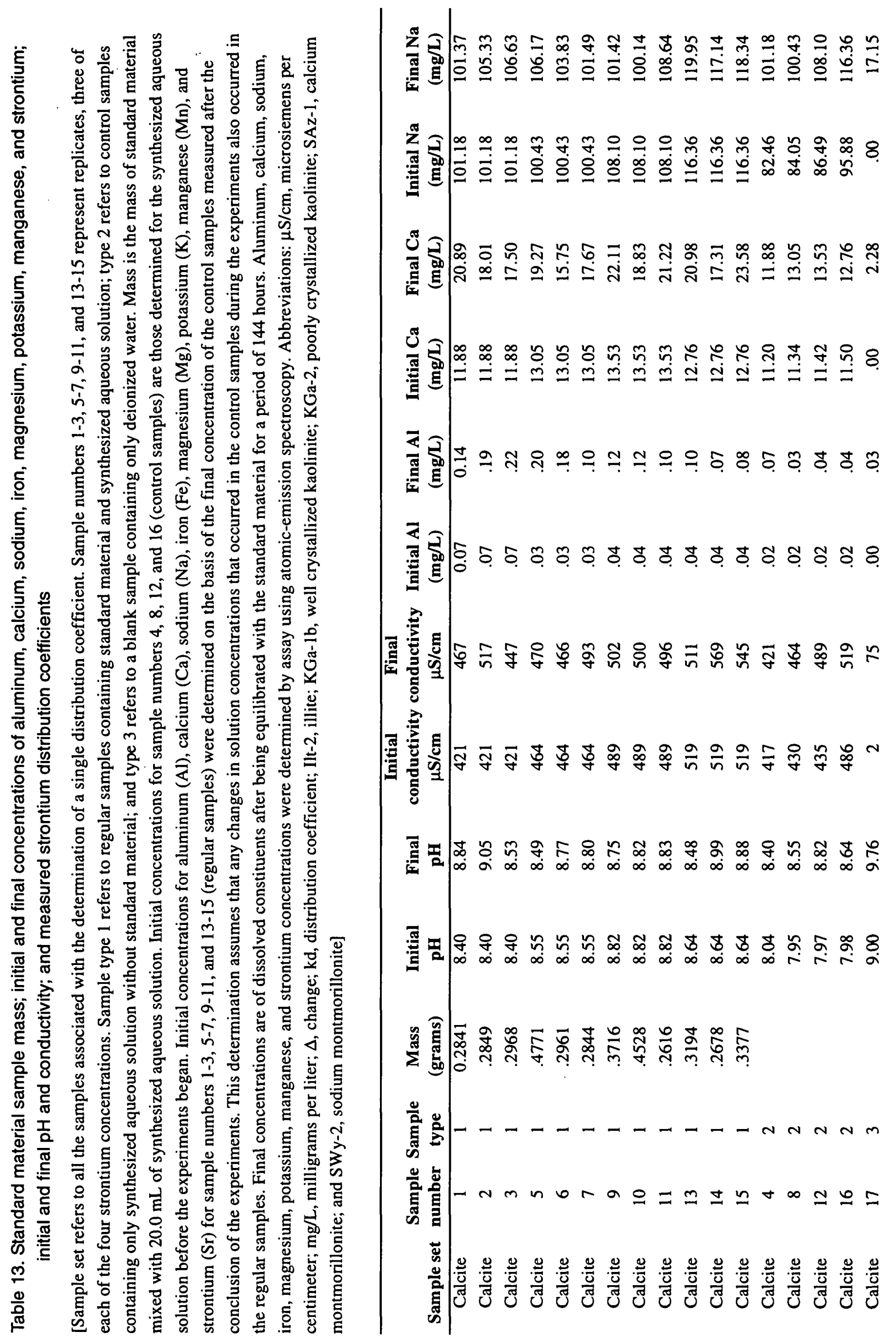


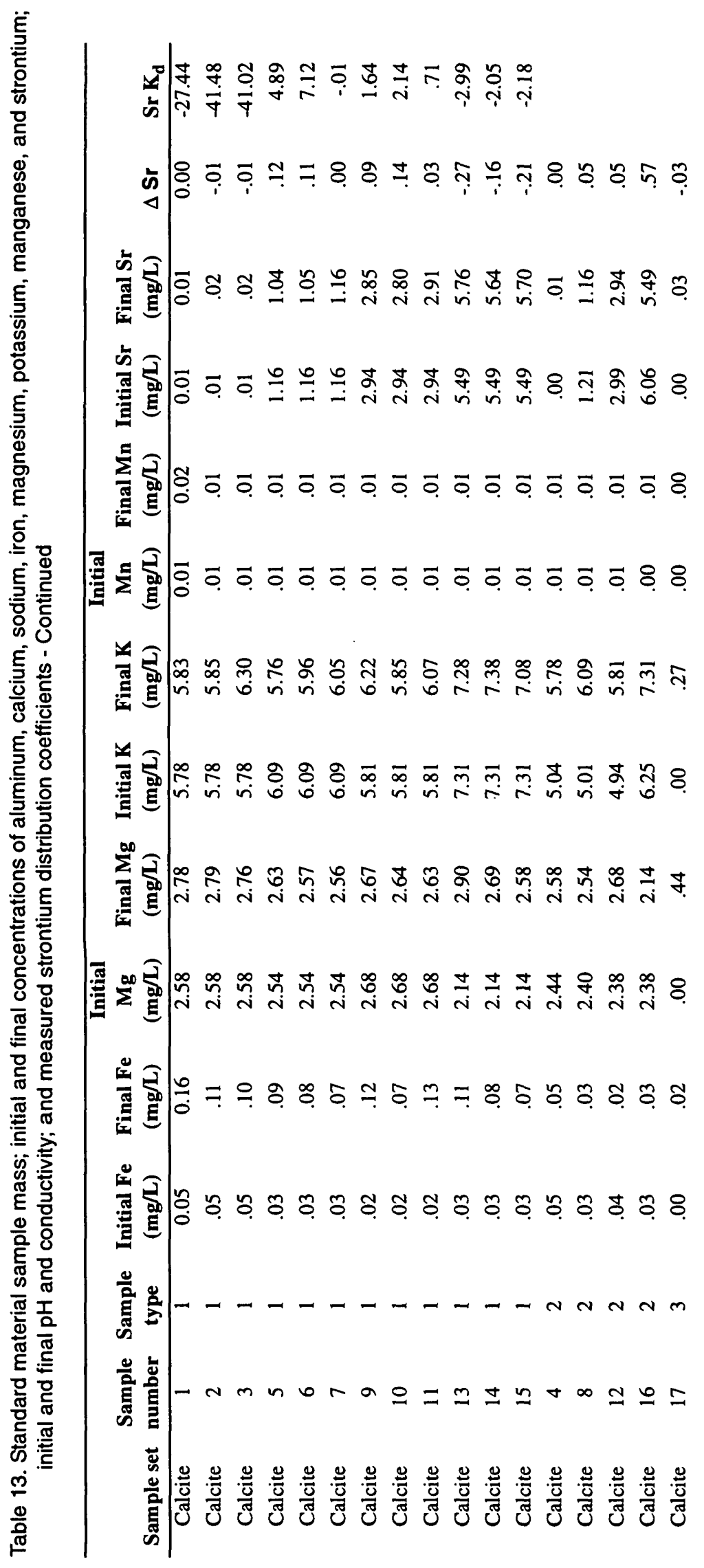




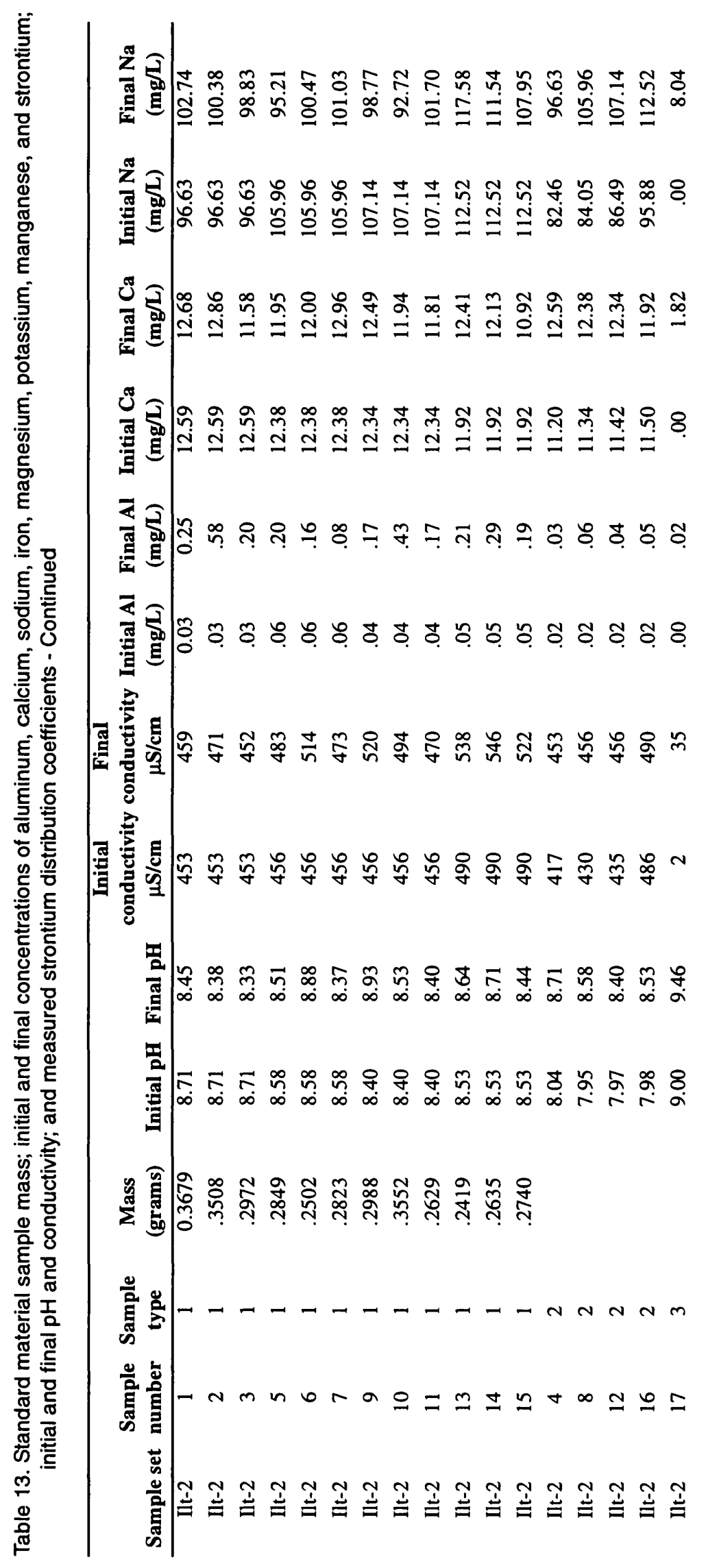




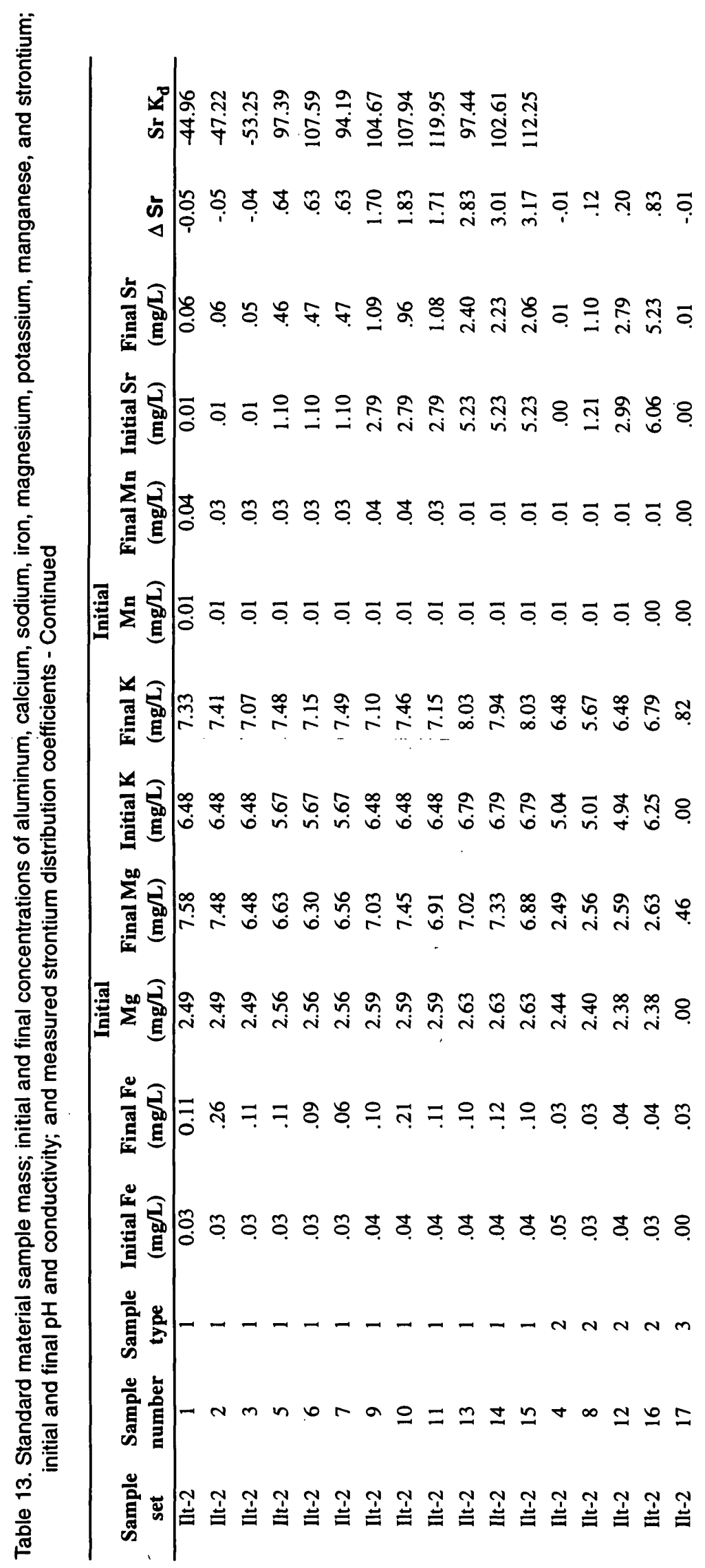




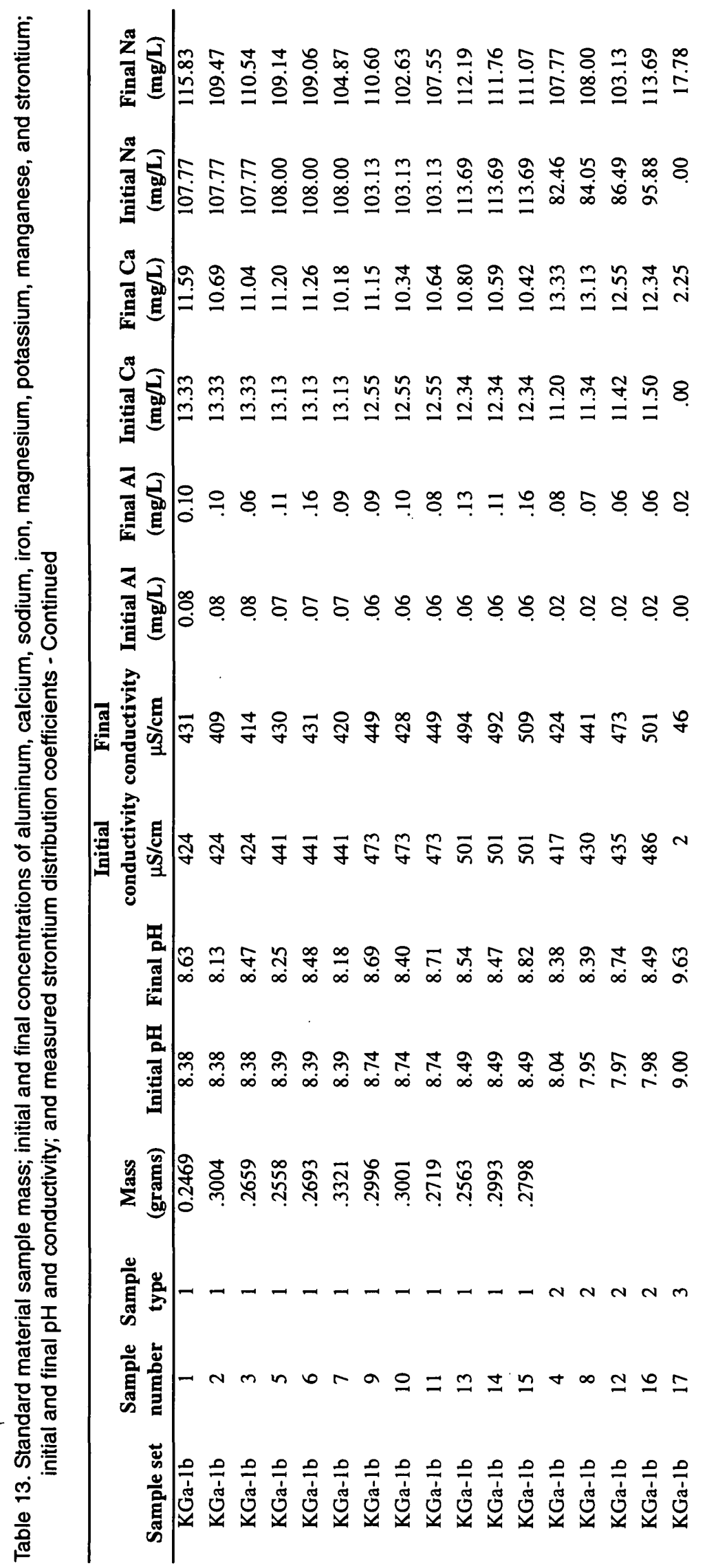




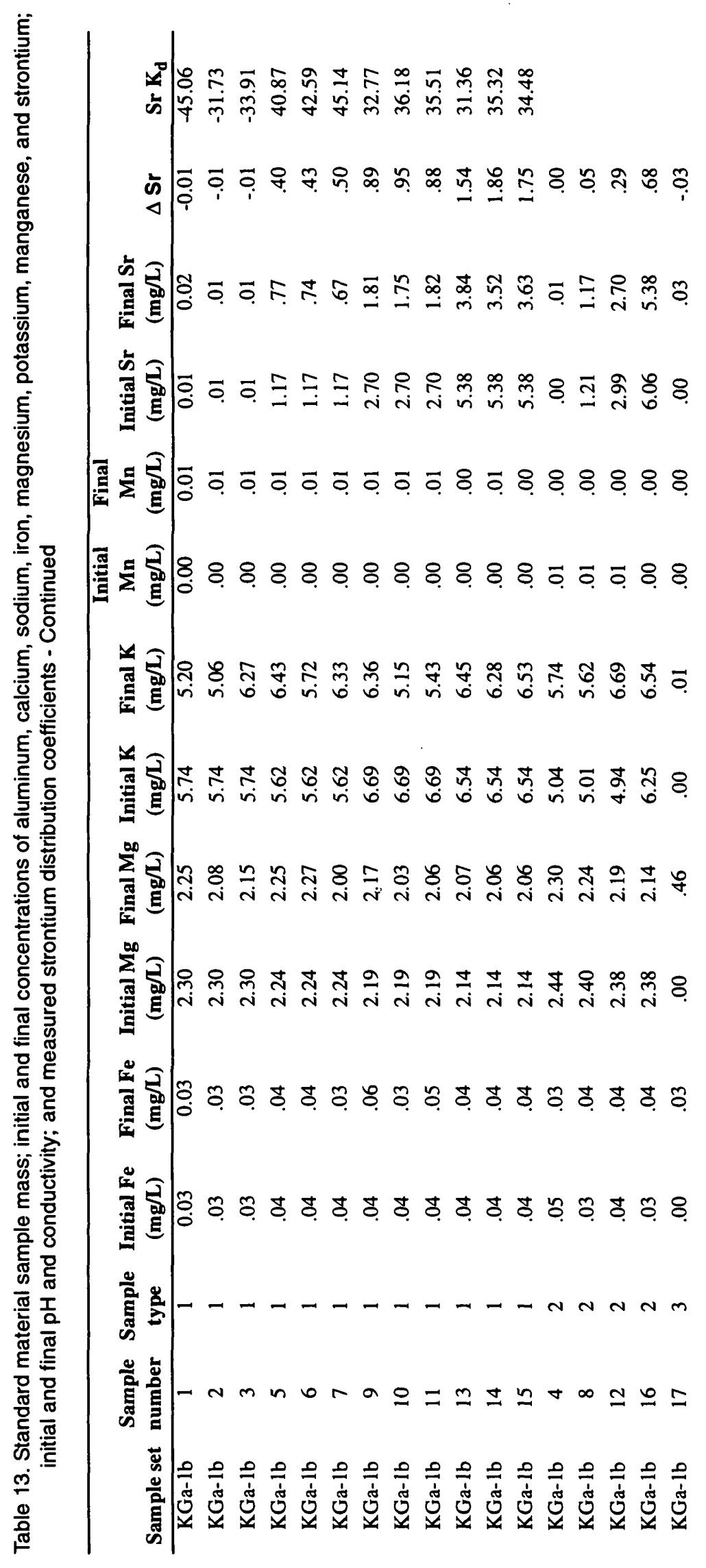




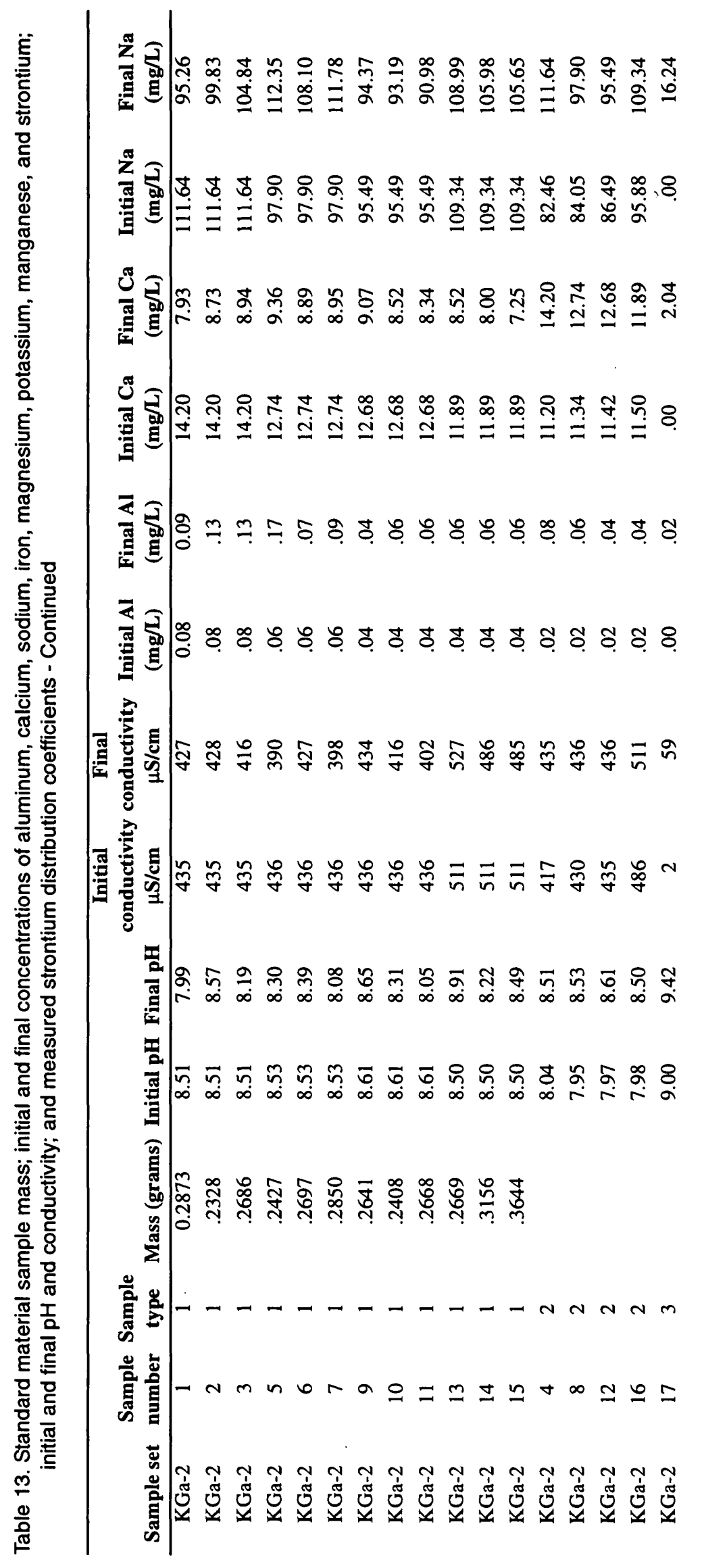




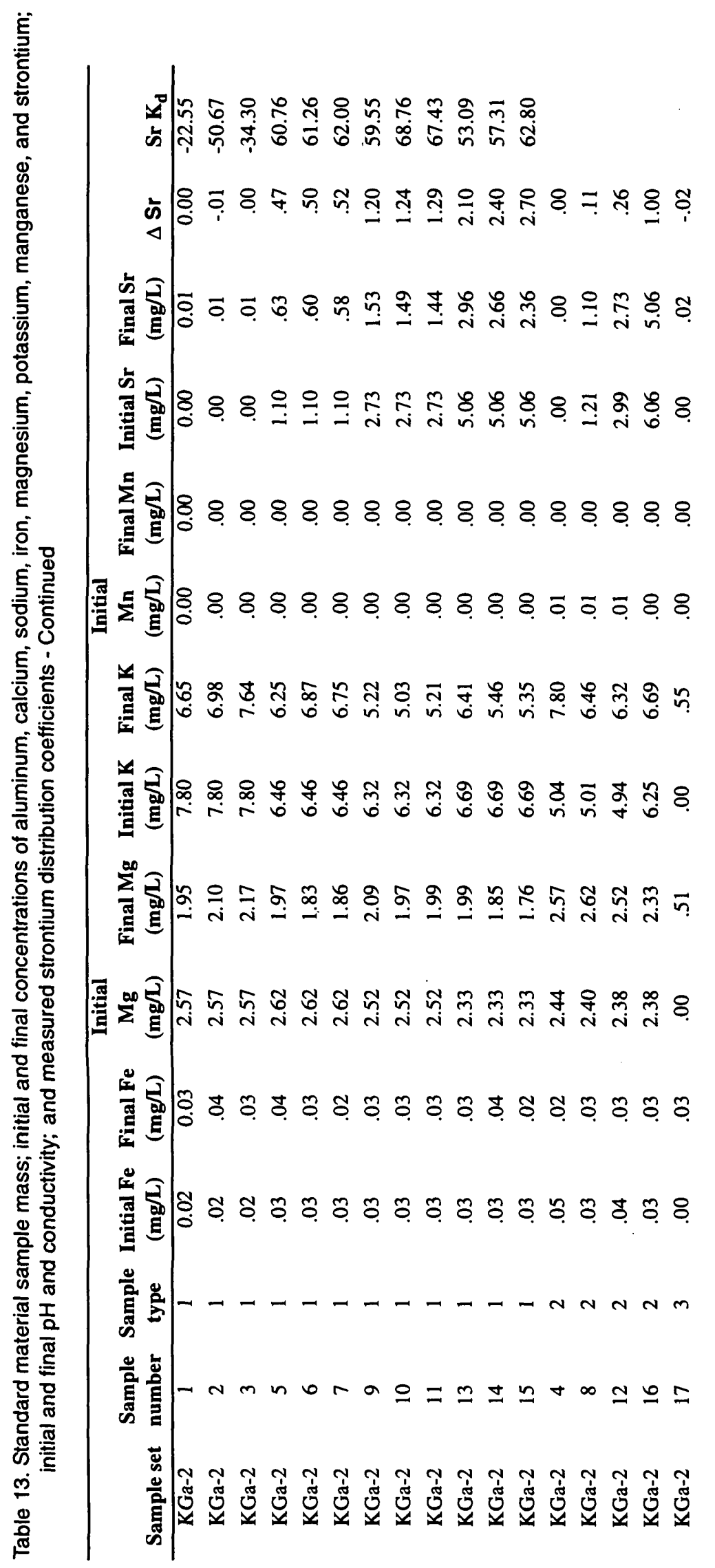




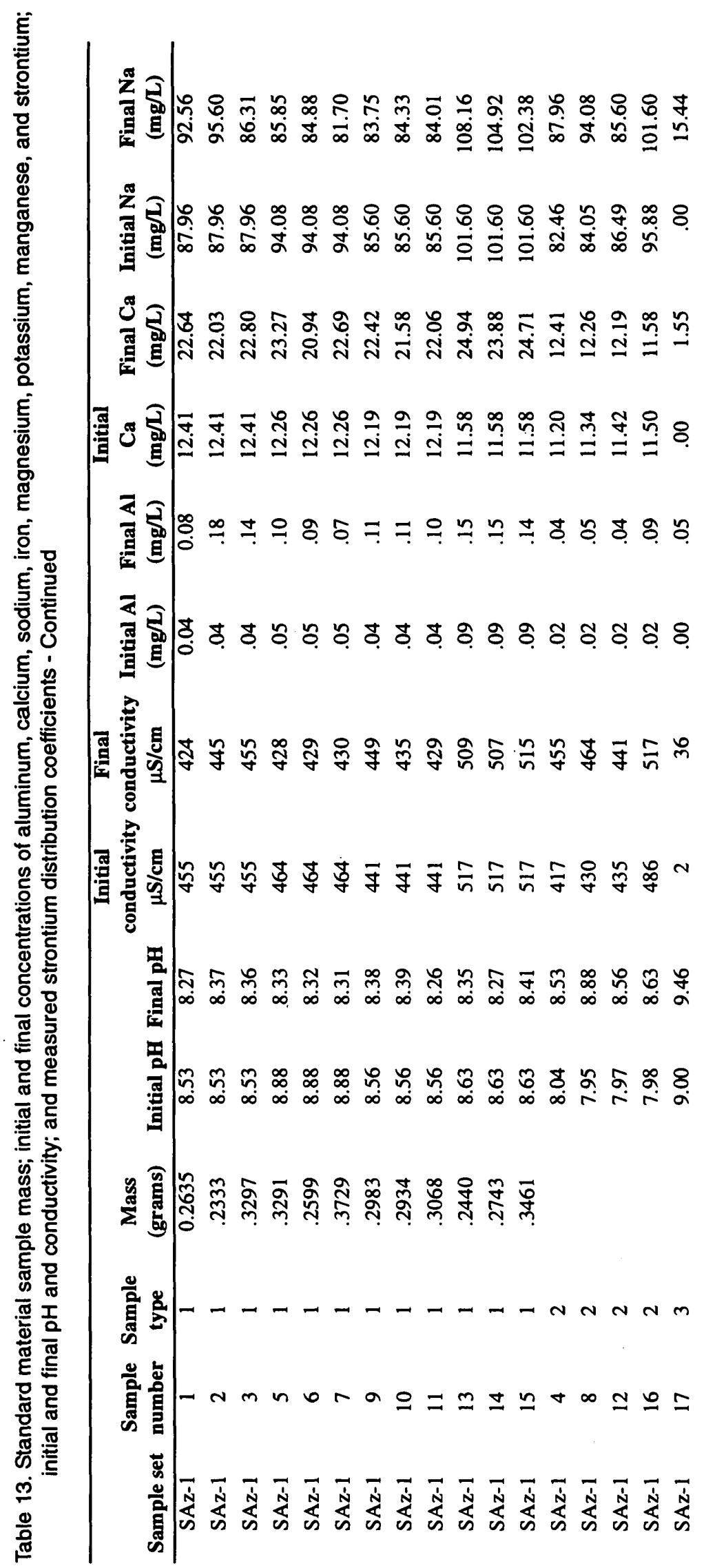




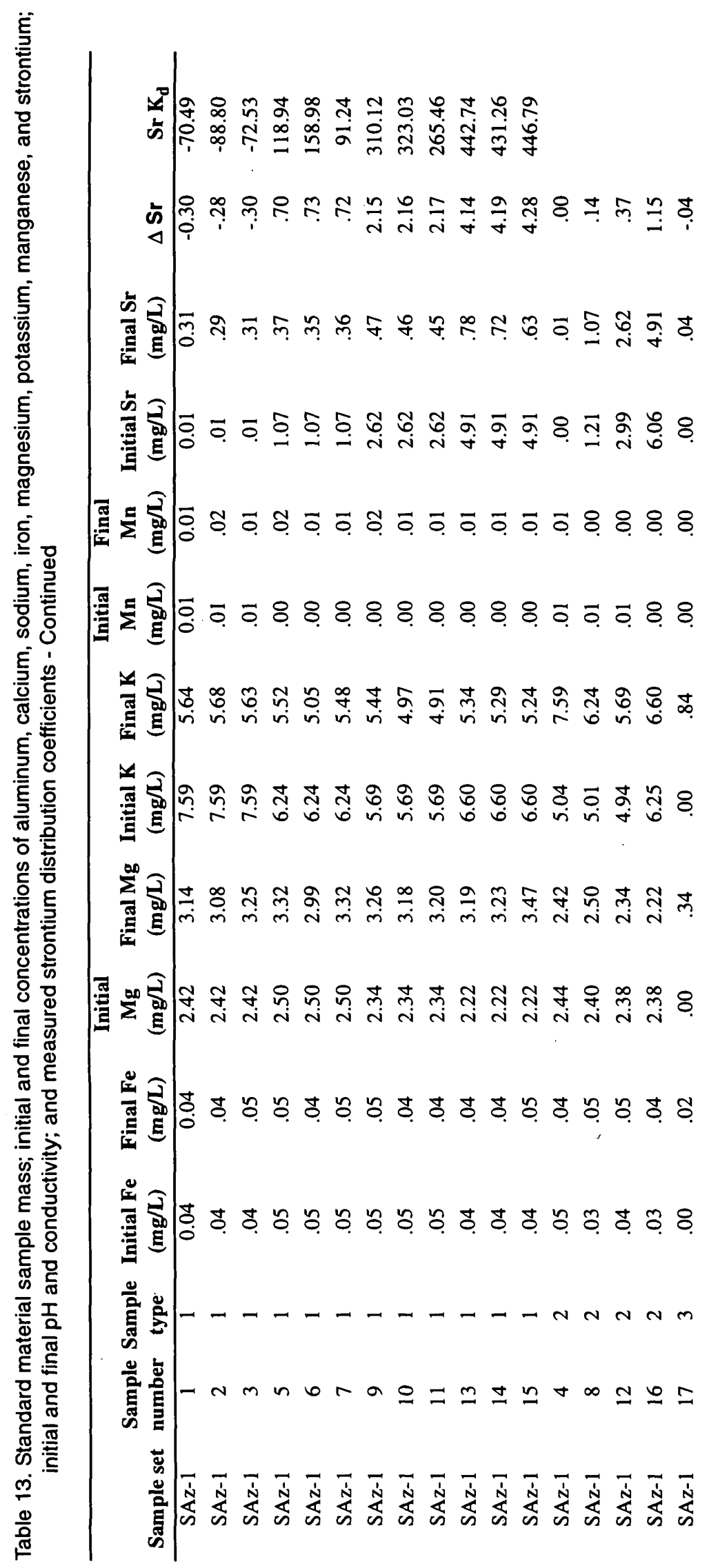




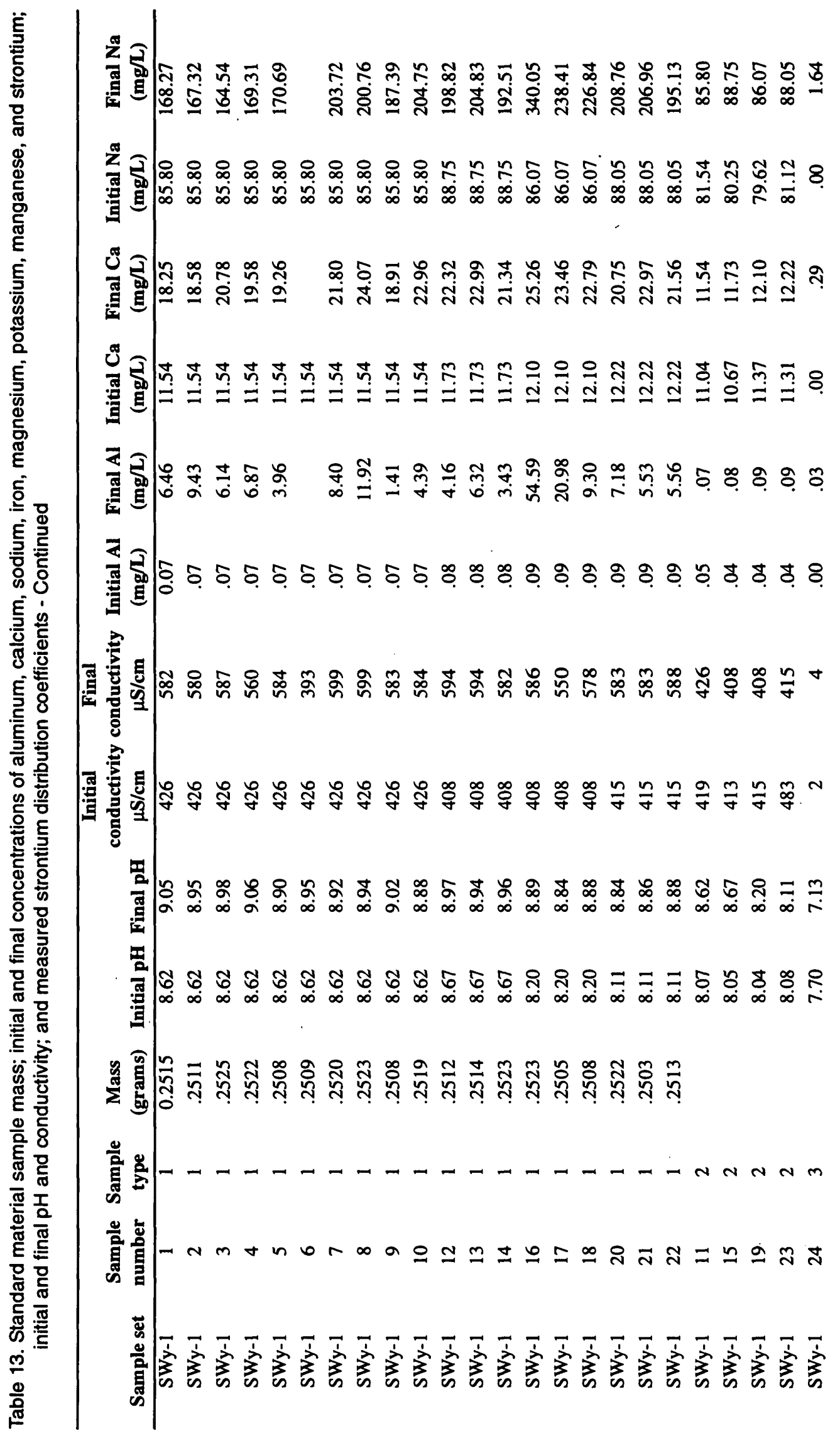




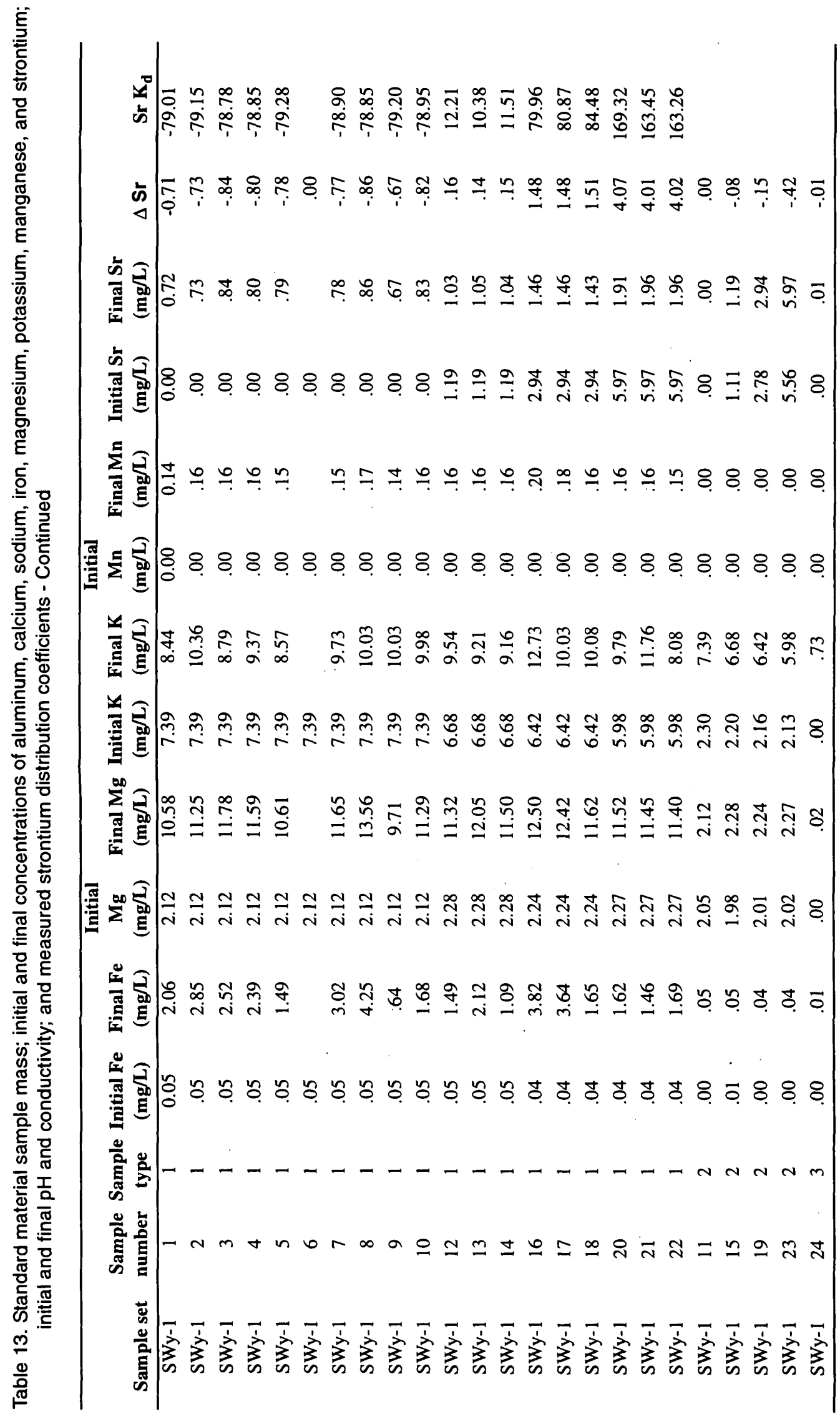

